\title{
Ressources tropicales : disponibilité et valeur alimentaire
}

\author{
H. ARCHIMÈDE ${ }^{1}$, D. BASTIANELLI ${ }^{2,3,4}$, M. BOVAL ${ }^{1}$, G. TRAN ${ }^{5}$ D. SAUVANT 6,7 \\ ${ }^{1}$ INRA, UR0143 Unité de Recherches Zootechniques, Domaine Duclos Prise d'eau, F-97170 Petit-Bourg, Guadeloupe \\ 2 INRA, UMR0868 Systèmes d'Elevage Méditerranéens et Tropicaux, 2 place Viala, F-34060 Montpellier, France \\ ${ }^{3}$ CIRAD, Systèmes d'Elevage Méditerranéens et Tropicaux, Campus International de Baillarguet, \\ F-34398 Montpellier, France \\ ${ }^{4}$ Supagro, Systèmes d'Elevage Méditerranéens et Tropicaux, 2 place Viala, F-34060 Montpellier, France \\ 5 Association Française de Zootechnie, 16 rue Claude Bernard, F-75231 Paris, France \\ ${ }^{6}$ INRA, UMR791 Modélisation Systémique Appliquée aux Ruminants, 16 rue Claude Bernard, F-75231 Paris, France \\ ${ }^{7}$ AgroParisTech, Modélisation Systémique Appliquée aux Ruminants, 16 rue Claude Bernard, F-75231 Paris, France
}

Courriel : Harry.Archimede@antilles.inra.fr

La riche biodiversité tropicale, la grande diversité de systèmes de production agricole dans le Sud ainsi que la présence de petites unités artisanales d'agro-transformation, contribuent à une large offre de ressources utilisables par les animaux. Ces ressources se caractérisent, inter et intrafamille, par une forte gamme de variations des valeurs alimentaires.

L'alimentation des populations humaines en forte croissance dans les Sud, alors que souvent, les besoins nutritionnels de base ne sont pas couverts, constitue un défi pour les années à venir. Pour ce faire, d'importants gains de productivité sont attendus dans les élevages du Sud qui doivent simultanément intégrer différentes contraintes, en particulier celles liées à la gestion de l'environnement. La productivité des élevages tropicaux (kg de viande ou de lait/tête de cheptel) est plus faible que celle des élevages de la zone tempérée respectivement de $44,75,13$ et $15 \%$ pour les productions de viande bovine, de lait, de viande de porc et de poulet de chair (Delgado et al 1999). Une partie de l'écart entre ces deux milieux peut s'expliquer par les finalités différentes des systèmes de production, l'effet dépressif du milieu tropical sur la qualité des ressources végétales et la productivité individuelle des animaux, le choix des modes d'expression de la productivité (performance individuelle plutôt que par unité de surface). Cependant, dans les Sud, intra-milieu d'élevage et intrasystème il existe de fortes variabilités de productivité. Des marges de progrès existent, qui concernent les différentes composantes du système de production dont les systèmes d'alimentation. Ces derniers sont à raisonner en tenant compte des nouvelles fonctions des systèmes de production dans le cadre d'une agriculture durable (Preston 2009) et des besoins des génotypes animaux les plus adaptés au milieu (Wilson 2009).
Dans les régions tropicales, comme dans les régions tempérées, la pertinence et la durabilité des systèmes d'alimentation sont en débat (Preston 2009). Aujourd'hui, la tendance serait à : 1) l'évaluation multicritère (c'est-àdire non strictement alimentaire) des ressources sur des indicateurs basés sur la multifonctionnalité des systèmes de production (Herero et al 2010); 2) l'adaptation des systèmes d'alimentation aux ressources disponibles. L'une des conséquences de ces débats devrait être l'élargissement de la gamme des ressources d'intérêt intégrant celles produites localement.

Une grande diversité de ressources végétales est traditionnellement utilisée et/ou potentiellement utilisable dans l'alimentation animale en zone tropicale (Preston 1995) : fourrages herbacés classiques (graminées et légumineuses, Roberge et Toutain 1999, Sotomayor et Pitman 2001), fourrages arbustifs (Leng 1997), coproduits fibreux de cultures (Chenost et Kayouli 1997), coproduits de l'agro-industrie, cultures plus ou moins spécialisées de céréales, plantes aquatiques, tubercules, fruits, protéagineux tropicaux, produits animaux, etc. La disponibilité, l'intérêt et le niveau d'utilisation de ces différentes ressources doivent être analysés au regard de la diversité des systèmes agricoles de production.

La tendance générale retrouvée dans la littérature est de caractériser les aliments par une valeur ou un ensemble de valeurs (composition chimique et digestibilité des différents composants) qui définissent la valeur nutritive. Cette dernière est basée sur des analyses de laboratoire (mesures chimiques, biochimiques ou enzymatiques), et/ou des mesures directes ou indirectes de la digestibilité. Une évaluation complète de la valeur alimentaire (VA) nécessite de connaître l'ingestibilité des ressources de façon à pouvoir estimer le flux de nutriments réellement disponible par l'animal (matière organique digestible ingérée...). Mais, les données d'ingestibilité sont plus rarement disponibles dans la littérature.

Pour une espèce animale donnée, la VA des ressources végétales est très variable intra et inter-ressources. Par ailleurs, certaines ressources sont potentiellement utilisables par de nombreuses espèces animales (poly et monogastriques) avec une plus ou moins grande efficacité à cause des spécificités de leur physiologie digestive. Les échelles de valeurs sont à nuancer en fonction des espèces animales et des objectifs des systèmes agricoles de production. L'autonomie des systèmes d'alimentation, les alternatives au soja se posent ainsi avec plus de force pour les élevages de monogastriques.

L'objectif principal de cet article est : 1) de présenter la grande diversité et la disponibilité des principales ressources alimentaires utilisées en zone tropicales pour les principales espèces animales 
d'élevage ; 2) d'analyser la variabilité de la VA intra-ressources et ses facteurs de variation ; 3) d'identifier les facteurs de progrès et les pistes de recherches sur ces ressources alimentaires.

\section{1 / Systèmes d'élevage et aliments}

La diversité des ressources utilisées dans un contexte donné est souvent inversement proportionnelle à la taille des cheptels et au degré de spécialisation des systèmes de production. Ces propos sont cependant à nuancer si on considère que dans la formulation d'aliments industriels l'optimisation technico-économique tend à favoriser l'utilisation de nombreuses ressources complémentaires. Aucune classification des systèmes d'élevage n'est pleinement satisfaisante. Un critère important est néanmoins la dépendance aux ressources naturelles (FAO 2009) qui est à la base de la classification initialement établie par Seré et Steinfield (1996) et reprise largement par les grandes organisations agricoles mondiales. Nous reprendrons donc ici la classification proposée par la FAO.

\section{1 / Systèmes de pâturage}

Les systèmes de pâturage qui prédominent en zone tropicale et dont la ressource principale sont les plantes herbacées, occupent environ $26 \%$ de la surface du globe non recouverte par les glaces (Steinfeld et al 2006). Au sein de ces systèmes de pâturage, des systèmes de pâturage extensifs occupent la plupart des zones sèches du globe, qui sont marginales pour la production agricole, dont les zones d'Afrique australe, d'Asie centrale, orientale et occidentale, de l'Australie et de l'Amérique du Nord. Ces surfaces supportent des ruminants (bœufs, moutons, chèvres et chameaux par exemple) pâturant principalement de manière itinérante. Ces systèmes représentent près de $7 \%$ de la production mondiale de viande bovine, environ $12 \%$ de la production de viande ovine et $5 \%$ de l'offre mondiale de lait. Les pâturages intensifs qui portent des fourrages cultivés d'excellente qualité et des densités plus fortes d'animaux, sont plus rares en zone tropicale. Ces surfaces cultivées représentent $3,8 \%$ de la superficie mondiale des terres et restent marginales, nécessitant une pluviométrie d'au moins 250-300 mm pour constituer un apport alimentaire supérieur à celui des pâturages naturels (Roberge et Toutain 1999). En zone tempérée et tropicale ces systèmes contribuent à $17 \%$ de la production mondiale de viande de bœuf, de veau et d'ovin et à $7 \%$ de la production mondiale de lait.

\section{2 / Systèmes agricoles mixtes}

Les activités de culture et d'élevage sont liées au sein de ces systèmes. Ils se définissent comme des structures dans lesquelles plus de $10 \%$ de la matière sèche qui alimente les animaux provient de sous-produits végétaux ou de chaumes, ou dans lesquels plus de $10 \%$ de la valeur totale de la production est issue d'activités agricoles qui ne sont pas liées à l'élevage. Ce sont principalement ces systèmes de taille variable, plus ou moins mécanisés, et intensifs qui consomment les Ressources Non Conventionnelles (RNC). Ces systèmes agricoles mixtes peuvent être pluviaux et irrigués. On y trouve entre autres, les systèmes d'élevages familiaux avicoles, ateliers secondaires au sein d'exploitations agricoles. En zone tropicale, les systèmes mixtes pluviaux sont localisés dans les régions subhumides de l'Afrique tropicale et de l'Amérique latine. Ce sont principalement des exploitations individuelles avec la présence de plusieurs espèces animales. À l'échelle mondiale, ils sont à l'origine de $53 \%$ de la production laitière, de près de $48 \%$ de la production de viande de bœuf, et de $33 \%$ de la production de viande de mouton. Les exploitations mixtes culture-élevage seraient la clé de la sécurité alimentaire car $2 / 3$ de la population mondiale vit de ces systèmes. Ils génèrent également la majeure partie des produits de l'élevage dans le monde en développement, soit $75 \%$ du lait et $60 \%$ de la viande. Par ailleurs, un milliard d'habitants de la planète sont nourris par des centaines de millions de petits agriculteurs ayant en moyenne 2 ha de cultures diversifiés et des éleveurs ayant moins de 5 têtes de gros bétail (Herero et al (2010).

En zones tropicales, les systèmes agricoles mixtes irrigués se trouvent dans les zones à forte densité de population : Asie de l'Est et du Sud. Ils contribuent pour un tiers de la viande de porc et de mouton, un tiers du lait et un cinquième de la viande de bœuf produits dans le monde.

\section{3 / Systèmes de production industriels}

Ils se définissent selon la FAO comme des structures qui achètent au moins $90 \%$ de leurs aliments (ou matières premières) pour animaux à d'autres entreprises. Ces systèmes sont intensifs et sont souvent proches des grands centres urbains. Ils sont courants en Europe, en Amérique du Nord, dans certaines régions de l'Asie de l'Est et du Sud-Est, en Amérique latine et au Proche-Orient. Ils sont en expansion des les régions tropicales. Les systèmes industriels portent souvent une seule espèce (bœuf, porc, volailles) alimentée par des céréales ou des coproduits industriels, des aliments de l'industrie acquis auprès de fournisseurs extérieurs.

Au niveau mondial, les systèmes industriels contribuent pour deux tiers de la production mondiale de viande de volaille, un peu moins des deux tiers de la production d'œufs et plus de la moitié de la production mondiale de porc. Leur importance est moindre en ce qui concerne la production de ruminants. La zone tropicale qui porte $70 \%$ du cheptel d'élevage ne consomme qu'environ $30 \%$ des céréales utilisées dans l'alimentation animale (Delgado et al 1999). Ces céréales ne sont pas toujours produites dans les pays concernés. Dans le Sud-Est asiatique qui est la région tropicale qui a développé les formes d'élevage les plus intensifs, les céréales contribuent pour moins de $45 \%$ à la formulation d'aliment concentré contre 60 à $80 \%$ pour les pays du Nord (Delgado et al 1999). D'autres ingrédients tels que les tubercules (manioc séché) et des coproduits de l'industrie contribuent à la formulation des aliments. Leur valeur nutritionnelle, leurs facteurs de variations et leurs contraintes d'utilisation, peuvent parfois être sensiblement différents de ceux des ressources utilisées en zone tempérée.

\section{2 / Fourrages et coproduits des cultures}

Les fourrages utilisés en zone tropicale se distinguent de ceux de la zone tempérée. Les graminées, dont la physiologie est en C4, ont une croissance et une lignification rapides dont il faut tenir compte pour leur gestion. Les légumineuses non sélectionnées peuvent contenir des métabolites secondaires qui affectent leur VA. Les coproduits de cultures peuvent représenter le principal ingrédient des systèmes d'alimentation. Les arbres fourragers sont aussi très présents dans certains systèmes d'élevage. Dans tous les cas, on observe une plus grande variabilité de la VA des ressources fibreuses en zone tropicale qu'en zone tempérée.

\section{1 / Disponibilité et valeur alimentaire des ressources fi- breuses}

\section{a) Les graminées}

Il existe une grande diversité de graminées en milieu tropical, adaptées à des environnements variés (sol, pluviométrie) (Sotomayor et Pitman 2001) que l'on retrouve aussi bien dans les ressources spontanées des savanes sèches que sur les prairies conduites de 
Figure 1. Histogramme des variations des teneurs en MAT des graminées tropicales (Base de données INRA-CIRAD-AFZ).

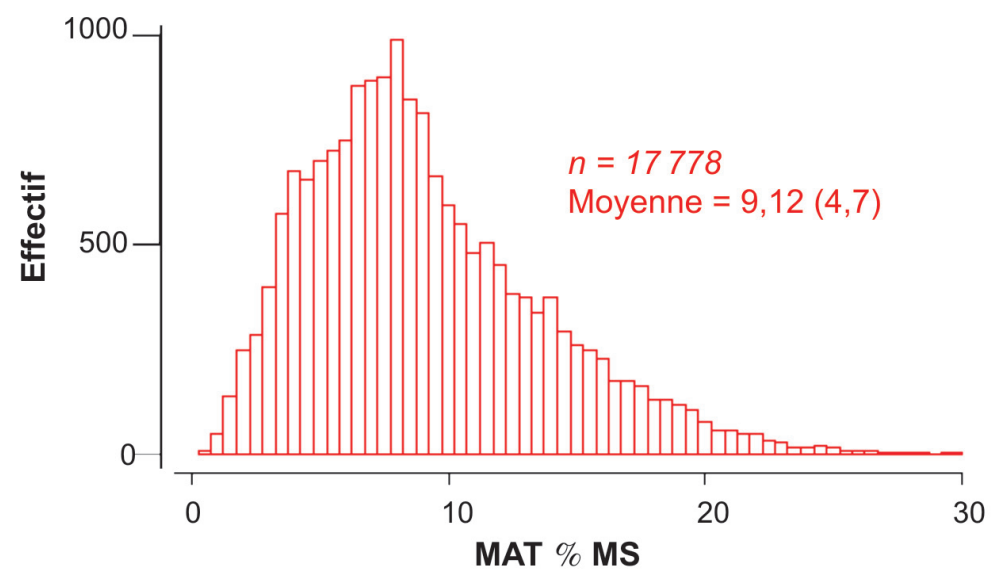

Figure 2. Relation entre les teneurs en NDF et MAT dans les fourrages tropicaux (Assoumaya 2007).

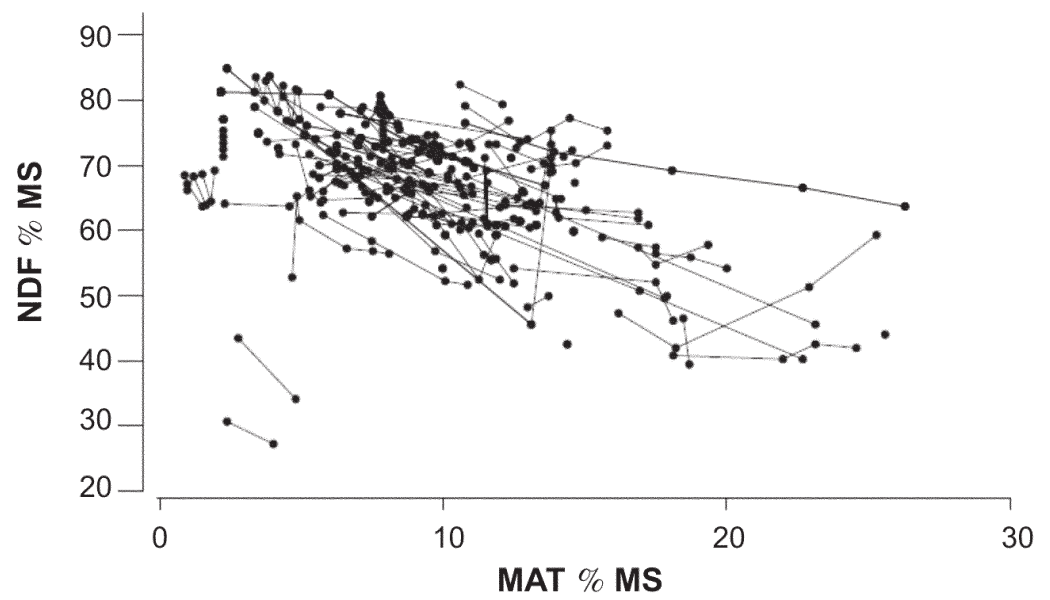

(tableau 1). Au sein des graminées, deux espèces Saccharum officinarum (canne à sucre) et Pennisetum Purpureum se distinguent pour leur productivité élevée. La canne à sucre se singularise aussi par des concentrations élevées en sucres solubles et en fibres et par de faibles teneurs en MAT.

Les graminées naturelles non cultivées, s'étendent sur des surfaces près de 7 fois plus étendues que les graminées sélectionnées, et sont largement présentes dans les zones inappropriées ou marginales pour les cultures, à cause des pluies insuffisantes ou des caractéristiques du sol. Une bonne part de ces espèces sont issues des prairies tropicales, savane, veld (Afrique du Sud) ou campo (Brésil). Ces graminées sont encore peu étudiées et seulement 100-150 espèces d'herbe dans le monde ont été sélectionnées sur approximativement 10000 espèces existantes (Nelson et Burns 2006). Avec une gestion adaptée à leur morphologie et une exploitation à un stade précoce, certaines peuvent avoir des VA équivalentes aux graminées sélectionnées avec des teneurs en MAT supérieures à $14 \%$ et des digestibilités atteignant $76 \%$ (Boval et al 2002). Les surfaces plantées de graminées sélectionnées, notamment celles implantées par graines (Panicum maximun, Bracharia mutica), sont en forte progression (au Brésil entre autres) et pourraient supplanter le Digitaria decumbens qui se diffuse par boutures. façon intensive dans les régions humides.

La VA des graminées tropicales a été très étudiée (Xandé et al 1989, Aumont et al 1995, Roberge et Toutain 1999), et est très variable. Assoumaya (2007) a relevé des ingestibilités qui variaient de 0,5 à $4,9 \%$ du poids vif et des digestibilités de 34 à $82 \%$. La teneur en Matières Azotées Totales (MAT) varie de 2 à $25 \%$ de la Matière Sèche (MS) avec une majorité de valeurs inférieures à $10 \%$ (figure 1). Les teneurs en parois végétales totales (NDF) sont inversement proportionnelles aux teneurs en MAT (figure 2).

La productivité des graminées varie en fonction des conditions de milieu, du niveau d'apport d'intrants, de l'espèce végétale. Les graminées cultivées pour constituer des prairies dans les zones de pluviométrie de $800-1200 \mathrm{~mm}$, sont généralement issues d'une vingtaine d'espèces sélectionnées pour leur productivité, leur pérennité et leur valeur nutritive (Roberge et Toutain 1999). En fonction du niveau d'intensification, les rendements s'étalent de 5 à $30 \mathrm{~T}$ de $\mathrm{MS}$, selon la pluviosité et l'irrigation
Tableau 1. Productivité (T MS/ha) des principales graminées et légumineuses cultivées en zone tropicale (Meyer et Denis 1999, Roberge et Toutain 1999, Prota base records).

\begin{tabular}{|c|c|c|c|}
\hline & \multicolumn{3}{|c|}{ Pluviométrie } \\
\hline & $400-1000 \mathrm{~mm}$ & $1000-1500 \mathrm{~mm}$ & $>1500 \mathrm{~mm}$ \\
\hline Graminées & & & \\
\hline Andropogon gayanus & $5-7$ & & \\
\hline Bracharia mutica & & $10-15$ & $20-25$ \\
\hline Bracharia ruziziensis & & $10-15$ & $10-15$ \\
\hline Chenchrus ciliaris & $6-9$ & & \\
\hline Chloris gayana & $5-7$ & & \\
\hline Digitaria decumbens & & $15-20$ & $20-25$ \\
\hline Panicum maximum & & $10-15$ & $20-25$ \\
\hline Panicum coloratum & $9-12$ & & \\
\hline Pennisetum purpureum & & $15-20$ & 30 \\
\hline Saccharum officinarum & $40-50$ & $50-60$ & $60-70$ \\
\hline Sorghum sp & $10-15$ & $15-20$ & $15-20$ \\
\hline Tripsacum laxum & & $10-15$ & $10-15$ \\
\hline Zea mays & & & $20-25$ \\
\hline Légumineuses & & & \\
\hline Alysicarpus ovalifolius & & $6-10$ & \\
\hline Centrosema pubescens & & $6-10$ & $7-10$ \\
\hline Clitoria tematea & 3-7 & & \\
\hline Dolichos labbab & $3-7$ & $6-10$ & \\
\hline Macroptilum lathyroides & & $6-10$ & $7-10$ \\
\hline Macroptilum atropurpureum & $3-7$ & & \\
\hline Pueraria javanica & & $6-10$ & $7-10$ \\
\hline Stylosantes guiyanensis & & $6-10$ & $7-12$ \\
\hline Stylosanthes hamata & $3-7$ & $6-10$ & \\
\hline Stylosantes humilis & $3-7$ & & \\
\hline Vigna Unguiculata & $3-7$ & & \\
\hline
\end{tabular}


Les graminées tropicales qui sont des plantes en C4 sont adaptées aux environnements chauds. Le réchauffement climatique et l'augmentation de la concentration en $\mathrm{CO}_{2}$ ne devraient que faiblement affecter l'offre de ces ressources (Thornton et al 2009). Ces graminées, outre leur intérêt alimentaire, présentent d'autres bénéfices pour l'environnement à exploiter dans le contexte actuel. Ainsi, certaines plantes, telles le Pennisetum purpureum et le Saccharum officinarum, sont des ressources majeures. Concernant la canne à sucre, son intérêt va au-delà de l'aliment et du puits de carbone. Cette ressource enrichit le sol en matière organique et c'est un précédent cultural d'intérêt pour les plantes à tubercules et le maraîchage. En matière de consommation d'eau, la canne à sucre développe sa production de biomasse sur 6 mois, ce qui peut correspondre à la durée de la saison des pluies ; elle s'enrichit en sucres après et maintient sa VA. Elle peut s'intégrer, comme banque d'énergie, dans des systèmes de production de milieux relativement secs.

Les surfaces pâturées et les parcours impropres aux cultures ont la capacité à stocker le carbone, presque autant que les forêts et les surfaces cultivées. Elles contribuent en outre à la biodiversité et participent à l'aménagement des territoires et des paysages (Nelson et Burns 2006). Grâce à leur multifonctionnalité, les pâturages ont donc une importance majeure, mais des règles de gestion plus efficientes et rationnelles sont nécessaires pour mieux les valoriser.

\section{b) Les légumineuses herbacées}

Les légumineuses herbacées sont en moyenne plus riches en protéines que les graminées alors que leur valeur énergétique est en moyenne inférieure à celle des graminées du fait de la lignification plus importante des tissus (Minson 1990). La productivité des légumineuses herbacées est de 1 à $2 \mathrm{~T}$ MS par ha et par mois de croissance en fonction des conditions de milieu et de l'espèce végétale. Comparativement aux graminées fourragères tropicales caractérisées par une large adaptation à des milieux contrastés, les légumineuses herbacées ont une adaptation plus localisée et spécifique (Sotomayor et Pitman 2001). La présence de légumineuses, plantes en $\mathrm{C} 3$, dans les prairies pourrait être favorisée par l'augmentation du $\mathrm{CO}_{2}$ (Thornton et al 2009). En plus de leur valeur alimentaire, l'intérêt des légumineuses est lié à leurs fonctions en tant que «plante de services». La fonction la plus ancienne est l'enrichissement des sols en azote. Outre ces fonctions, les légumineuses sont désormais intégrées dans les systèmes de cul- ture pour la lutte biologique contre certains pathogènes (nématodes) du sol via les sécrétions racinaires. En zone tempérée, la production de méthane d'animaux consommant des légumineuses est en général plus faible que celle d'animaux ingérant des graminées (Beauchemin et al 2009). Des résultats similaires ont été obtenus avec certaines légumineuses tropicales (Tiemann et al 2008). Le potentiel des légumineuses à réduire la production de méthane proviendrait de la présence de composés secondaires (tanins, saponines) (Rochefort et al 2008).

\section{c) Les arbres fourragers et feuillages}

Les feuillages des arbres et d'arbustes de familles botaniques très diversifiées (Speedy 1991) peuvent être utilisés en alimentation animale, dans des contextes allant de l'utilisation en période de soudure alimentaire dans les parcours secs, par exemple au Sahel, jusqu'à la culture d'arbustes spécifiquement pour l'alimentation animale. La teneur en MAT des feuilles peut atteindre 15 à $20 \%$ de la MS.

Dans des contextes favorables d'exploitation, les feuillages ont 4 caractéristiques potentiellement importantes pour l'alimentation des ruminants (Leng 1997) : une biomasse de qualité et de digestibilité élevée ; un apport de nutriments pour assurer la croissance microbienne du rumen et améliorer la digestion de la biomasse cellulosique quand les rations sont déséquilibrées; une source de protéines by-pass digérées dans l'intestin; une source de vitamines et de minéraux afin de corriger les carences de la ration de base. La présence chez certaines légumineuses arbustives (avec une forte variabilité intra-espèce) de facteurs antinutritionnels (composés métabolites secondaires) en quantité importante peut limiter leur consommation (Machin et Nyvold 1992, Leng 1997) voire même conduire à des intoxications. L'accumulation de ces produits secondaires dans les plantes dépend du stade de récolte, et de réactions adaptatives au milieu (sol, pathogènes, prédateurs...) (Foley et al 1999).

Certains arbres fourragers pourraient contribuer à la réduction de la production de méthane du fait de la présence des composés secondaires (Tiemann et al 2008).

Certaines espèces d'arbres sont valorisables par les ruminants et les monogastriques (Preston 2006). L'utilisation des feuillages pour l'alimentation des monogastriques non herbivores, dont les porcs, à fait l'objet de différentes études dont certaines très récentes
(Leterne et al 2006, Regnier 2011). La digestibilité peut être importante dans le cas de feuilles jeunes. La valeur protéique des ressources est très variable mais demeure toujours faible comparativement aux ressources protéiques classiques (tourteau de soja). Les croissances maximales atteintes sont d'environ $300 \mathrm{~g} / \mathrm{j}$ chez le porc en croissance (Rodriguez et al 2009). La quantité et le profil d'Acides Aminés (AA) des feuillages peuvent être très éloignés de ceux effectivement disponibles pour les animaux suite à la digestion. Par ailleurs, la valorisation maximale des feuillages nécessite que la ration de base soit pauvre en fibres. Ces ressources sont utilisées dans les systèmes non industriels.

En dehors de l'apport d'aliments pour les animaux, les arbres et arbustes ont d'autres fonctions: bois de chauffage, matériaux de clôture et de construction, sources de molécules pharmacologiques et autres, aliments (fruits) pour l'Homme ; engrais verts et mulch, abris et ombrage, habitat pour la vie sauvage, valeur paysagère. Les arbres contribuent aussi à protéger les sols contre l'érosion hydrique et du vent et à recycler les nutriments (chute et décomposition des feuilles). Enfin, ils peuvent constituer des puits de carbone. L'ordre d'importance de chacune de ces fonctions dépend du pays, voire de la région et du système de production. Pour les petits agriculteurs des pays du Sud, les arbres sont avant tout des sources de produits alimentaires et de bois de chauffe.

\section{d) Les coproduits fibreux des cultures}

Les coproduits fibreux des cultures alimentaires de l'Homme, valorisables avant tout par les herbivores, constituent un groupe hétérogène d'aliments du bétail. Leur valeur alimentaire varie fortement en intra et inter-ressources (tableau 2). Les pailles (céréales, canne à sucre), qui constituent probablement la ressource la plus abondante au sein de ce groupe, se caractérisent par une faible valeur protéique (MAT $<60 \mathrm{~g} / \mathrm{kg}$ MS), vitaminique et minérale, une faible ingestibilité (de 25 à $50 \mathrm{~g} / \mathrm{PV}^{0,75}$ chez le mouton) et une faible digestibilité $(<50 \%)$ entraînant une faible valeur énergétique $(<7,5$ MJ énergie métabolisable/kg MS). Quand les coproduits fibreux constituent l'unique ingrédient de la ration ils peuvent à peine couvrir les besoins d'entretien d'un animal adulte. De plus, la paille de riz se différencie de celle des autres céréales par sa moindre teneur en lignine et sa richesse en silice (Van Soest 2006). Les nouvelles variétés de paille de riz ont tendance à être plus feuillues mais les feuilles sont légèrement moins 
Tableau 2. Caractéristiques (composition chimique, ingestibilité) de quelques coproduits de cultures relevées dans la littérature.

\begin{tabular}{|l|c|c|c|c|}
\hline \multicolumn{1}{|c|}{ Ressources } & $\begin{array}{c}\text { Productivité } \\
(\mathrm{T} / \mathrm{ha})\end{array}$ & $\begin{array}{c}\text { MAT } \\
(\%)\end{array}$ & $\begin{array}{c}\text { NDF } \\
(\%)\end{array}$ & $\begin{array}{c}\text { Ingestibilité } \\
(\% \mathrm{PV})\end{array}$ \\
\hline Paille de Riz & 4 & $2-4$ & $70-80$ & $1,0-2,7$ \\
Canne de Mais & 5 & $1,1-4,7$ & $65-91$ & \\
Canne de Sorgho & 4,6 & $1,0-7,8$ & $57-83$ & \\
\hline Bagasse de Canne & $10-20$ & $<3$ & $86-88$ & \\
Paille de Canne & $2-5$ & $<4$ & $75-90$ & \\
Amarre de Canne & $8-16$ & $<6$ & $63-67$ & $1,7-2,0$ \\
\hline Pseudo tronc de Banane & 4,8 & $1,5-3,5$ & $61-66$ & $1,3-2,4$ \\
Feuille Bananier & 1,2 & $8,2-12,4$ & $44-61$ & $1,8-3,6$ \\
\hline
\end{tabular}

bien digérées que les tiges. Le rapport feuille tige varie fortement (35 à $80 \%$ de feuilles dans la biomasse récoltée) avec les conditions de culture, les espèces et les variétés.

Les pailles peuvent être exploitées directement par pâturage après culture, ou après collecte et stockage. Une complémentation (énergétique, azotée et minérale) est nécessaire pour aboutir à une meilleure utilisation digestive. D'autres coproduits fibreux présentent une VA beaucoup plus riche que les pailles. Ainsi la teneur en azote des feuillages de patate douce, manioc, arachide... après récolte des tubercules ou des graines, est supérieure ou égale à celle des légumineuses fourragères. Certaines ressources comme le manioc peuvent cependant nécessiter un fanage pour éliminer des facteurs antinutritionnels.

Les coproduits de cultures sont disponibles principalement sur les exploitations de type polyculture-élevage très représentées dans la zone tropicale. Les pailles (céréales, canne à sucre...) et autres coproduits fibreux peuvent représenter jusqu'à $5 \mathrm{~T}$ MS/ha de culture. La croissance de la population humaine dans les pays du sud et en voie de développement entraînera une diminution de la disponibilité des terres pour la production de fourrage et risque d'accroître la dépendance des ruminants aux coproduits des cultures.

Certaines ressources peuvent être valorisées par d'autres usages comme les mulch organiques, les litières pour les animaux. Certains coproduits fibreux peuvent aussi contribuer à l'autonomie énergétique des exploitations agricoles. Ainsi, on peut envisager de fractionner la biomasse totale produite par la canne à sucre entre les différentes composantes plus ou moins riches en sucres, en fibres ou en lignine. La fraction la plus lignifiée (la bagasse), la plus onéreuse à complémenter, peut être utilisée pour la production d'énergie à la ferme. Ce procédé pourrait être élargi à d'autres ressources.

\section{2 / Facteurs de variation de la valeur alimentaire}

Les facteurs de variation de la VA sont d'abord directement liés aux caractéristiques chimiques (teneur en eau, MAT, NDF, minéraux) et physiques (composition morphologique, longueur des organes) des fourrages.

La gestion des ressources (le choix de l'espèce, l'âge de repousse ou le niveau de fertilisation) et les divers traitements technologiques, font varier les caractéristiques physico-chimiques des ressources et donc leur VA. Celle-ci dépend par ailleurs du milieu (sol, saison) sur lequel il est difficile d'agir et elle varie aussi selon les espèces animales et ou leur stade physiologique. Certains facteurs de variation sont déterminants quel que soit le système d'alimentation et d'autres sont davantage relatifs à l'alimentation avec des fourrages distribués à l'auge, ou directement pâturés.

a) Les caractéristiques physicochimiques

La teneur en MAT est un déterminant majeur de la VA des fourrages tropicaux, notamment pour la digestibilité, mais aussi pour l'ingestion. L'impact sur l'ingestion serait majeur pour les fourrages dont la teneur en MAT est inférieure à $10 \%$ (Minson 1990). Selon Assoumaya et al (2007) qui a synthétisé l'information sur près de 800 fourrages, l'augmentation des teneurs de MAT entre 5 et $10 \%$ améliore la digestibilité et l'ingestion des fourrages. Dans le cas des légumineuses, les teneurs en MAT sont les premiers facteurs déterminant l'ingestibilité. Au pâturage, la teneur en MAT influence également la digestibilité (Boval et al 2002a et b), et dans une moindre mesure l'ingestion, en particulier pour des fourrages jeunes, de moins de 2 semaines de repousse. Dans ce cas, même avec des teneurs en MAT élevées allant même jusqu'à 14\%, l'ingestion peut être limitée (figure 3). D'autres paramètres davantage liés à la préhensibilité de fourrages jeunes sont alors des facteurs limitant l'ingestion. Par ailleurs, le seuil critique de $8 \%$ de MAT, n'est pas forcément un facteur limitant au pâturage, l'animal se constituant généralement une ration plus riche en MAT que celle du fourrage proposé. L'analyse des fèces indique en effet des teneurs en azote supérieures à celles du fourrage proposé, en particulier pour des teneurs inférieures à $10 \%$.

La teneur en NDF présente une double influence sur la digestibilité et sur l'ingestibilité des ressources alimentaires, inverse de l'influence de la teneur en MAT (Assoumaya 2007). Les fourrages très riches en parois végétales ont le double handicap d'être peu ingestibles et peu digestibles. L'influence des parois sur l'ingestibilité résulte des phénomènes d'encombrement du tube digestif, du rumen en particulier. Elle résulte également de l'encombrement buccal car le travail masticatoire quotidien est limité à environ 1000 minutes/jour. De ce fait, plus le travail masticatoire exigé est important moins l'animal va ingérer de MS. En conséquence, différents critères ont pu être proposés pour prévoir l'encombrement et l'ingestibilité : NDF,

Figure 3. Evolution des quantités ingérées de matière organique (MOl, \% Poids vif) par des génisses en fonction de la teneur en matières azotées du fourrage pâturé (MAToff) à différents stades repousse (7, 14, 21, 28 jours) (Boval non publié).

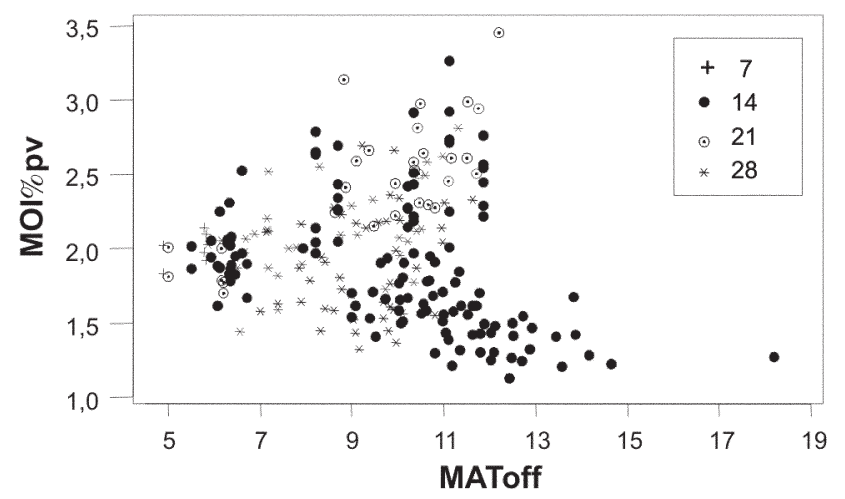


Figure 4. Evolution de la matière organique ingérée digestible $(M O D I)$ et de la digestibilité de la matière organique (DMO), en fonction des teneurs en NDF du fourrage proposé au pâturage (Boval non publié).

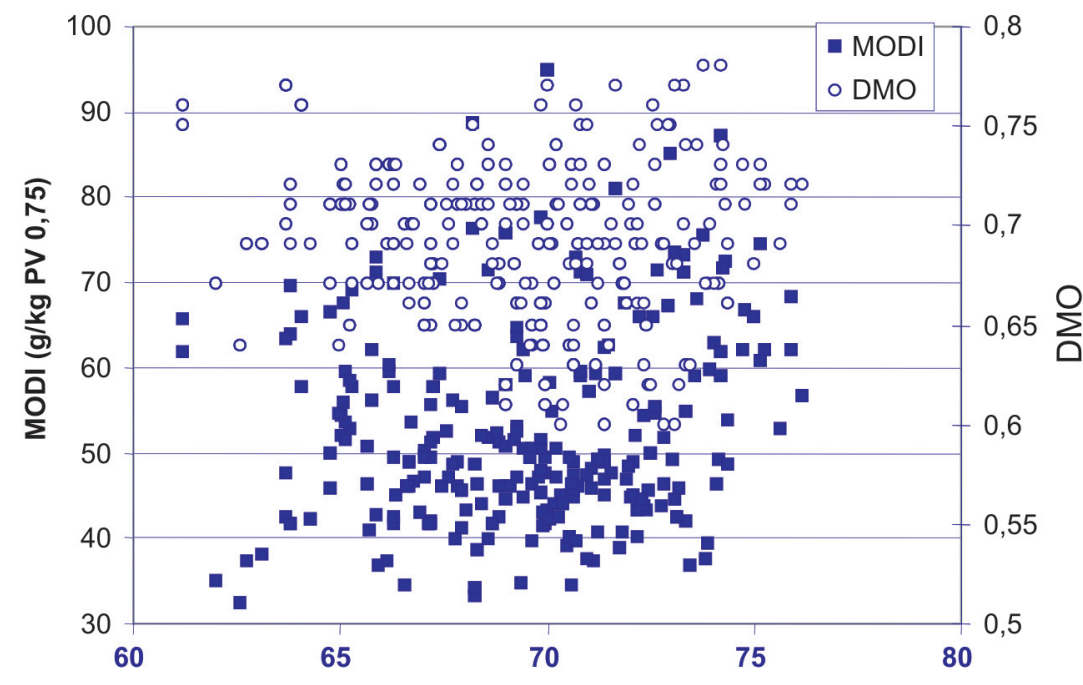

Teneurs en NDF (\%MO)

NDF non digestible, dMO, temps de mastication/kgMSI. Au pâturage, pour des teneurs en NDF allant de 60 à $75 \%$ de MO, la teneur en NDF n'influence pas forcément la digestibilité (figure 4). Comme pour les teneurs en MAT, l'animal peut sélectionner sa ration et les variations de composition chimique du fourrage proposé influencent moins le régime qu'à l'auge.

La composition morphologique des fourrages est aussi un déterminant pour l'alimentation, à l'auge comme au pâturage car, d'une part elle est corrélée à certains critères de la composition chimique, d'autre part au pâturage la présentation du fourrage sur pied et le comportement sélectif des animaux orientent la qualité de la ration prélevée quand les quantités d'aliments proposées sont supérieures aux besoins. Les quantités ingérées augmentent avec la longueur des plants pâturés (tiges et feuilles).

La teneur en MS influencerait selon certains auteurs l'ingestibilité des fourrages (Minson 1990). Selon Archimède (1999), il y a un effet sur l'ingestion des fourrages verts quand la teneur est inférieure à $20 \%$ et il s'agit donc davantage d'un effet seuil. Au pâturage, dans divers essais réalisés avec des génisses ou des moutons, la teneur en MS variant de 20 à $35 \%$ influence peu l'ingestion. En revanche, on observe dans certains cas une baisse de la digestibilité quand la teneur en MS augmente, de l'ordre de 1,6 points de digestibilité/\% de MS (Boval non publié).

b) La gestion agronomique des fourrages, gestion de l'alimentation

L'analyse de données portant sur 1313 fourrages de la région Caraïbes et de la Réunion (Aumont et al 1995) montre que l'espèce fourragère explique 20,6 et $30,6 \%$ de la variance des teneurs en MAT et des digestibilités estimées in vitro et $19,7 \%$ de la variabilité des quantités ingérées. Cette variabilité entre espèces est toutefois plus réduite que celle engendrée par diverses modalités de gestion d'une même espèce. Elle est notamment bien inférieure à la variabilité expliquée par d'autres facteurs de gestion, comme l'âge de repousse. Au pâturage, des différences existent aussi entre espèces et celles qui sont sélectionnées sur la base de leur productivité ou de leur valeur nutritive ne sont pas forcément les mieux ingérées (Boval 2008).

Pour les coproduits de culture tels que les pailles de céréales il y a aussi une variabilité liée à la variété mais elle serait moindre que celle induite par différents effets de l'environnement. Au sein d'une population de blé du MoyenOrient la part de variabilité de la VA liée aux cultivars (qui se manifeste surtout au niveau morphologique) a été estimée à $20 \%$ (Schiere et al 2004). Des observations similaires ont été faites avec la paille de riz. La sélection génétique des céréales au cours de ces dernières années a contribué à développer des variétés avec des rendements plus élevés des grains par rapport aux pailles, sans affecter la valeur nutritive des pailles. Les teneurs en silice et en lignine sont respectivement le premier et deuxième facteur limitant de la digestion des pailles de riz (Schiere et al 2004). Depuis une décennie, les programmes de sélection de ces cultures prennent en compte la qualité des résidus sans compromettre les objectifs initiaux associés : le rendement en grain et la résistance aux stress. En Inde, des petits exploitants ont augmenté la production laitière des buffles et des vaches de près de $50 \%$ tout en maintenant leur niveau de production de riz (Herero et al 2010).

L'âge de repousse est un facteur de variation majeur de la VA des graminées, influençant la composition chimique, sa digestibilité et son ingestibilité. Ce dernier critère est le facteur qui varie le plus avec la maturation de la plante. Elle diminue en moyenne de $0,13 \mathrm{~g}$ à $0,75 \mathrm{~g}$ de $\mathrm{MS}$ par kilo de $\mathrm{P}^{0,75}$ par jour de repousse suivant les auteurs (Minson 1990, Aumont et al 1995, Assoumaya 2007). Les différences s'expliquent pour beaucoup par l'amplitude des âges de repousse des fourrages expérimentaux. Ces auteurs indiquent par ailleurs que la relation entre l'ingestion et l'âge de repousse est de type curvilinéaire, illustrant une rapide maturation du fourrage au cours du premier mois. L'âge de repousse influence moins les légumineuses que les graminées, avec un effet modéré sur la teneur en MAT qui descend rarement en dessous de $8-9 \%$ de MAT/kg MS. Au pâturage, l'âge de repousse constitue également un facteur déterminant de la VA, mais intervient différemment, comparativement à l'auge. Si à un stade précoce, le fourrage est mieux digéré comme à l'auge, il est en revanche mieux pâturé et consommé à 28 jours (Boval et al 2007). Quand le fourrage est jeune, il est plus feuillu et plus digestible quel que soit le milieu d'alimentation, mais au pâturage, ce fourrage est moins préhensible qu'un fourrage plus mature et la quantité ingérée de MS par bouchée est alors réduite.

La fertilisation a un impact direct sur la composition du fourrage. La fertilisation azotée notamment accroît la teneur en MAT et la quantité de biomasse produite et diminue la teneur en MS des fourrages (Minson 1990). La fertilisation azotée peut expliquer les fortes teneurs de MAT $(>12 \%)$ des graminées incluant de l'azote minéral.

Au pâturage, l'impact de la fertilisation a surtout été évalué sur les gains de croissance, pouvant aller pour des bovins de 1,3 à $4,7 \mathrm{~kg} \mathrm{PV} / \mathrm{ha} / \mathrm{an}$, par $\mathrm{kg}$ d'azote/ha (Mears et Humphreys 1974). Boval et al (2002b) rapportent un gain de $21 \%$ des quantités ingérées et digérées par des bovins sur des parcelles fertilisées (50 Unités d'Azote), comparées à des surfaces non fertilisées de Dichanthium spp. Dans cette étude, le gain a été permis, non pas par un accroissement de la MS proposée (comparable sur les 2 types de parcelles), mais par une élongation considérable des tiges et des feuilles, à la fois très 
préhensibles et de bonne qualité. La fertilisation peut ainsi être un levier de gestion efficace mais à un coût environnemental que l'on doit considérer dans le contexte actuel. La fertilisation organique en général, dont le vermicompost, serait une alternative intéressante, pour produire des effets comparables à moindre coût (Chanda et al 2010).

Les quantités proposées des fourrages distribués peuvent influencer le tri et donc la digestibilité et l'ingestion (Zemmelink et Mannetje 2002). En augmentant les quantités proposées de 2 à $3 \mathrm{~kg}$ MS/jour, Fanchone et al (2010) ont mesuré des quantités ingérées et digérées accrues de $13 \%$, les animaux ayant développé un comportement sélectif à l'auge. Au pâturage, une relation curvilinéaire a été mise en évidence entre les quantités de fourrage disponible ( $\mathrm{kg} / 100 \mathrm{~kg}$ de poids vif) et les gains de poids journaliers de bovins (Humphreys 1991). Cependant certaines études ciblées sur la mesure des quantités ingérées n'indiquent pas d'effet significatif des quantités proposées sur la VA (Boval et al 2000). La morphologie particulière de certains fourrages et notamment leur grande hétérogénéité verticale pourrait expliquer ces différences (Cruz et Boval 2000).

c) Les traitements physiques, chimiques et biochimiques, et la complémentation

La VA des fourrages, celles des fourrages pauvres notamment (dont les pailles), peut être significativement améliorée par différents traitements physiques et/ou chimiques (Van Soest 2006). L'ingestibilité des ressources est davantage améliorée que la digestibilité. La digestibilité peut être augmentée de $30 \%$ et l'ingestibilité de $50 \%$, la matière digestible ingérée pouvant augmenter jusqu'à $50 \%$.

Certains traitements physiques (vapeur à haute pression) permettent d'augmenter la digestibilité des pailles de riz de 16 à 30\% (Van Soest 2006). Ils nécessitent des équipements importants et ne sont ni pratiques ni rentables pour les agriculteurs. Aujourd'hui, les traitements chimiques $\left(\mathrm{NaOH}, \mathrm{NH}_{3}\right.$ ou de l'urée...) semblent être plus pratiques pour un usage agricole. Les traitements à l'urée, à l'ammoniac, à la soude, augmentent la digestibilité de 18,31 et $50 \%$ respectivement (Van Soest 2006). Ces traitements peuvent cependant poser des problèmes de sécurité pour les utilisateurs et l'environnement.

Les traitements alternatifs pour améliorer la valeur nutritive de la paille sont l'utilisation de champignons lignolytiques ou d'enzymes spécifiques dégra- dant la cellulose et/ou l'hémicellulose. Les résultats sont variables (0 à $20 \%$ d'augmentation de la dégradation) et des travaux complémentaires incluant notamment des estimations économiques sont encore nécessaires sur cette technologie (Sarnklong et al 2010).

Outre les traitements, les pailles (céréales, canne à sucre) requièrent une complémentation (énergétique, azotée et minérale) pour une meilleure utilisation digestive. Simultanément, la complémentation de la ration de l'animal s'impose.

Classiquement le fanage et l'ensilage sont utilisés comme des modes de conservation qui n'améliorent pas la VA des ressources. Dans certains cas de ressources riches en certains composés secondaires (précurseurs d'acide cyanhydrique), le fanage permet d'en réduire les concentrations. L'ensilage permet de réduire les taux d'oxalate dans certaines ressources.

La complémentation de fourrages pauvres par des feuillages permet d'améliorer la qualité des rations consommées par les animaux. Patra (2008, 2009) a réalisé des méta-analyses sur l'effet de la complémentation de fourrages pauvres avec des feuillages pour les rations de ruminants. Les principales conclusions sont: 1) la digestibilité de la matière organique des rations augmente, suivant une loi de type linéaire. Les lois de réponse à la teneur en MAT du fourrage de base et de la ration sont de type quadratique avec un optimum atteint avec $14-15 \%$ de feuillages dans la ration ; 2) la digestibilité de la MAT de la ration est affectée par le pourcentage de feuillages dans la ration, la teneur en MAT et la quantité de MAT apportées par les feuillages, la teneur en NDF des feuillages ; 3) l'ingestion maximale de $\mathrm{MO}$ et de protéines digestibles sont atteintes avec respectivement 37 et $42 \%$ de feuillages dans la ration.

L'optimum des propriétés catalytiques (amélioration des conditions ruminales impactant positivement la digestion du fourrage de base) est atteint avec $16 \%$ de feuillages dans la ration, alors que du fait de la réponse sur l'ingestion, $42 \%$ de feuillages dans la ration sont nécessaires pour atteindre l'optimum des performances animales (Patra 2008, 2009).

\section{d) Les facteurs agropédoclimatiques}

Les sols, le climat et la saison affectent la productivité et la composition des fourrages avec des différences entre espèces. Ces dernières sont plus ou moins adaptées aux différents milieux.
En saison chaude, Guérin (1999) reporte des baisses de MAT, CB et dMO plus marquées, qu'en saison fraîche, pour du Panicum maximum exploité à des âges de repousse allant de 4 à 8 semaines. Les productions mesurées de MS de Panicum maximum ont été par ailleurs plus importantes qu'en saison fraîche (130 vs $50 \mathrm{~kg} \mathrm{MS} / \mathrm{ha} / \mathrm{j})$. En saison fraîche, la photopériode généralement plus réduite intervient sur la croissance des graminées avec des différences entre les espèces végétales.

La température induit par ailleurs des gains de production de MS qui expliquent les différences marquées de biomasse entre graminées tropicales et tempérées. Mais dans le même temps ces températures élevées engendrent des baisses de digestibilité de l'ordre de 0,6 et 0,2 point de digestibilité (exprimée en \%) par ${ }^{\circ} \mathrm{C}$ pour les graminées et légumineuses, respectivement (Minson 1990).

L'environnement climatique (température, eau...) fluctuant serait le principal facteur expliquant la variabilité observée dans la qualité des pailles. Les températures élevées entraînent une accumulation de lignine dans les parois végétales (Wilson 1994) mais dans des proportions variables en fonction du type physiologique de l'espèce végétale et de l'organe considéré. L'accumulation de lignine est moindre chez les plantes dont la tendance est de rester feuillue quand des températures trop basses pénalisent leur croissance comparativement à celles qui initient des fleurs et/ou des graines. L'absence de floraison et/ou de production de graines maintient les sucres solubles dans les feuilles et les tiges dont la VA est alors faiblement pénalisée. Ainsi les cultures de céréales se développant dans des conditions climatiques pénalisant la production de graines auront tendance à avoir des pailles de meilleure qualité.

\section{3 / Matières premières et coproduits de l'agro-indus- trie}

Une partie des ressources utilisées en milieu tropical se retrouve aussi dans les pays du Nord. Certaines matières premières sont cultivées dans les deux zones (maïs, soja...). D'autres matières premières font l'objet d'un commerce important du Sud vers le Nord (manioc, certains tourteaux...). Certains sousproduits correspondent à des utilisations communes de ressources produites localement ou importées (son de blé, drêches de brasserie industrielles ...). 


\section{1 / Disponibilité}

\section{a) Céréales et susbtituts}

Le maïs et le sorgho sont les seules céréales qui font l'objet de cultures spécifiquement destinées à l'alimentation animale dans certains contextes tropicaux, principalement en Amérique du Sud. En Afrique, les céréales utilisées en alimentation animale sont issues de cultures avant tout destinées à l'alimentation humaine et leurs marchés sont donc étroitement liés. La composition de ces céréales (maïs, sorgho...) est proche de celles de la même famille de ressources produites en zone tempérée.

La stratégie de développement de monocultures de céréales pour l'alimentation animale suivant le même schéma intensif que celui des pays du Nord fait l'objet de nombreux questionnements sur leur durabilité, même avec des génotypes adaptés aux régions tropicales. Ces cultures généralement fortes consommatrices d'intrants (eau, engrais, produits phytosanitaires...) dont la disponibilité et l'accessibilité (prix, transport...) peuvent être limitants, diminueront vraisemblablement dans le futur. Cependant, les cultures de céréales peuvent être intégrées à des systèmes de cultures durables en complémentarité avec d'autres ressources cultivées pour restaurer la fertilité des sols (Preston 1995).
Des alternatives aux céréales existent dans le monde tropical : racines, tubercules et fruits amylacés ; sucre de canne et palme, huile de palme, etc. (Machin et Nyvold 1992, Preston 1995, Pérez 1997). La principale caractéristique des aliments alternatifs aux céréales est leur carence en protéines, alors que leur valeur énergétique est proche de celle des céréales. La production peut atteindre 5 à $10 \mathrm{~T} \mathrm{MS} / \mathrm{ha}$ en fonction des conditions de culture. Ces ressources sont valorisables, selon leur préparation, aussi bien par les ruminants que par les monogastriques.

Parmi les alternatives aux céréales, il convient de différencier les coproduits des cultures et les ressources issues de cultures spécialisées à des fins d'alimentation animale. Comme les céréales, certaines monocultures (manioc, patates douces...) posent des problèmes de durabilité et de concurrence avec l'alimentation humaine. Leur gestion raisonnée pour une optimisation de la production globale (prélèvements réguliers de feuilles vertes et récolte des racines et tubercules) accroît l'opportunité de ces cultures dans les systèmes de production (Wanapat 2009). Le sucre (jus) de canne, le sucre et l'huile de palme peuvent localement constituer des solutions durables dans le contexte des systèmes agroforestiers. Des systèmes d'alimentation à petite échelle, de porcs notamment, peuvent être développés autour de ces ressources.

\section{b) Protéagineux et susbtituts}

Les protéagineux sont des ressources bien équilibrées en protéines et en énergie, pouvant être bien valorisées en alimentation animale. Les teneurs en protéines varient entre 20 et $40 \%$ de la MS. Le potentiel d'utilisation des graines pour l'animal comme source de protéine et d'énergie, ne dépend pas uniquement des concentrations en acides aminés et en énergie digestible. Les équilibres très variables entre acides aminés (figure 5 ) et la présence ou non d'éléments antinutritionnels doivent être pris en compte. Les principaux facteurs antinutritionnels des graines de légumineuses sont les inhibiteurs de protéase, les lectines et les tanins. Certains polysaccharides non amylacés peuvent également pénaliser la valeur nutritionnelle.

La grande diversité des espèces de légumineuses, notamment tropicales, permet une culture dans des milieux et des conditions très variés : sols, climats, durée des cycles, etc. La culture de légumineuses peut être bénéfique dans des cultures menées en association ou en rotation avec les céréales, puisque leur capacité à fixer l'azote permet un enrichissement du sol.

Cependant, les protéagineux sont principalement cultivés à des fins d'alimentation humaine dans la plupart des régions tropicales: Asie, Amérique du Sud, Afrique. Les genres Phaseolus

Figure 5. Equilibre entre acides aminés (g/100 g d'acides aminés) dans certaines ressources alimentaires.

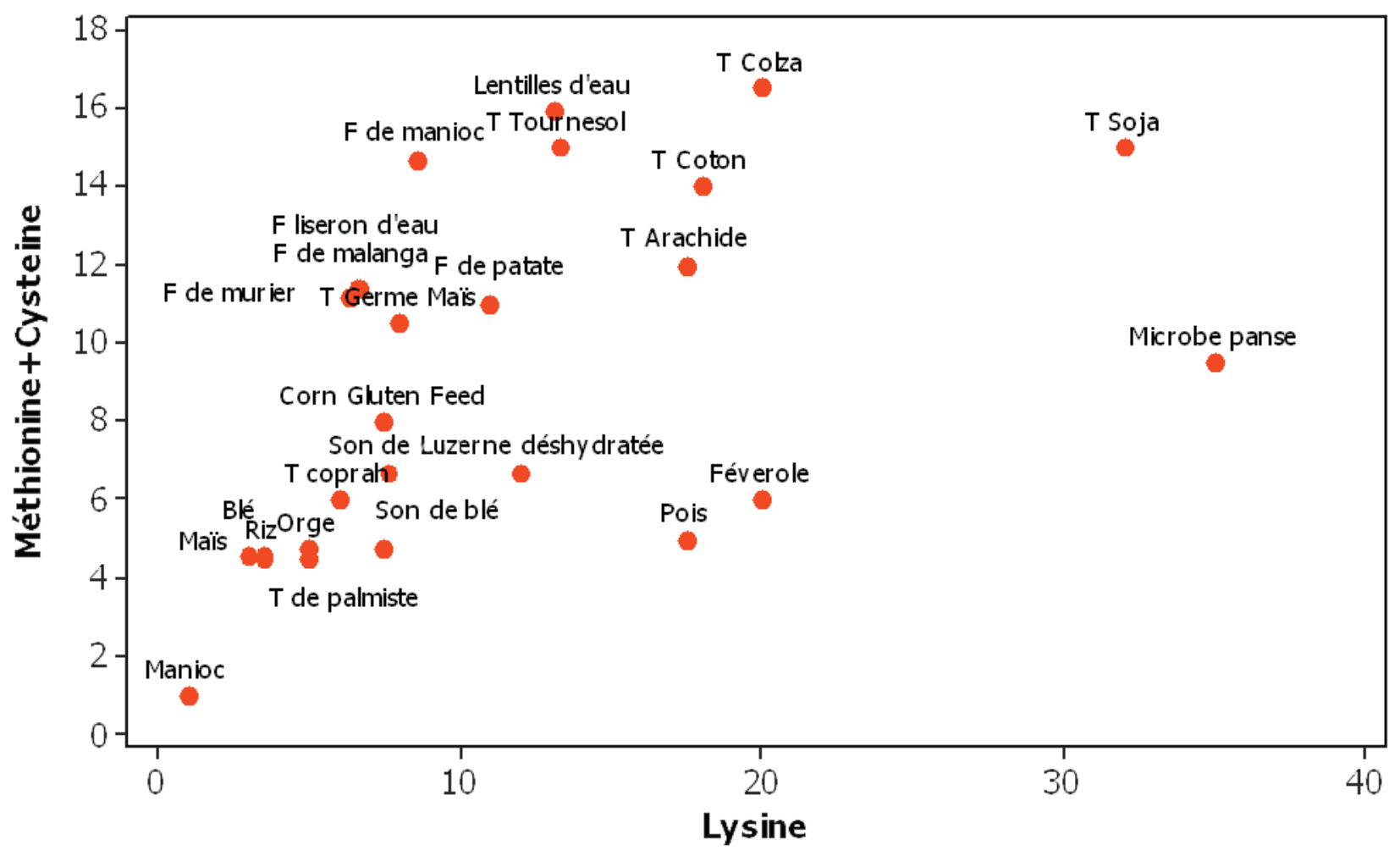


(haricots), Vigna, Cajanus (pois d'angole), Lablab (dolique) prédominent. Les graines rejetées pour la consommation humaine sont consommées par les animaux (Mekbungwan 2007). Le soja et l'arachide occupent une place à part en tant que légumineuses oléagineuses essentiellement utilisées après extraction de l'huile.

Les prix souvent élevés des graines sur les marchés locaux les disqualifient parfois pour l'alimentation animale. Sur le plan technique, la présence de facteurs antinutritionnels, peut imposer certains traitements avant consommation. Cependant, les qualités agronomiques des légumineuses à graines et leur valeur alimentaire en font des candidats essentiels pour une promotion accrue de leur utilisation dans le cadre de perspectives d'intensification écologique.

\section{c) Coproduits de l'agro-industrie}

Le traitement domestique, artisanal ou industriel des ressources alimentaires (céréales, oléagineux, tubercules...) génère des sous-produits qui sont traditionnellement utilisés en alimentation animale. Les tourteaux sont quasiment les seuls coproduits à faire l'objet d'un échange commercial à grande échelle.

La disponibilité de ces sous-produits augmente théoriquement avec la population et donc avec la demande alimentaire. En réalité, elle peut également baisser lorsque les pays substituent l'importation de produits finis à celle de produits bruts, comme par exemple la farine à l'importation de blé. Dans ce cas, les sous-produits bénéficient aux pays exportateurs et non à la filière locale.

La disponibilité des coproduits peut donc être évaluée à la hausse dans le futur, mais leurs caractéristiques peuvent varier selon l'évolution du type d'industries. Dans un certain nombre de pays africains, les grandes industries (moulins, huileries) ont fait place dans les dernières décennies à des ateliers de taille plus modeste générant une production plus atomisée et plus variable de sous-produits. Les sous-produits d'origine industrielle sont généralement assez comparables à ceux qui existent dans les pays du Nord.

\section{d) Farines animales}

Le commerce à grande échelle des farines de poissons industrielles a provoqué une surpêche dans certaines régions du monde et ne pourra pas se développer en proportion des besoins des productions animales et aquacoles intensives (FAO 2009). Cette ressource sera donc limitée dans le futur. Au niveau local en revanche, des filières de production de farine de poisson à base de pêche locale ou de sous-produits de l'alimentation humaine peuvent se développer et proposer des produits intéressants pour l'alimentation animale. Toutefois la qualité sanitaire de ces produits, qui sont fragiles, peut être potentiellement dégradée.

Les farines de viande et de sang ont des valeurs nutritives très intéressantes pour l'alimentation animale. Suite aux problèmes sanitaires majeurs survenus en Europe dans les années 1990 (crise de l'Encéphalopathie Spongiforme Bovine), les farines de viandes ont été interdites dans l'alimentation animale. Cependant, dans d'autres contextes réglementaires et en évitant le cannibalisme (recyclage des déchets au sein de la même espèce), les farines animales peuvent constituer une ressource utile.

\section{e) Utilisation des ressources humides}

L'utilisation de ressources non séchées est relativement limitée dans les pays du Nord, mais peut être plus facile dans les pays du Sud, au sein des structures d'exploitation de taille réduite. En effet, cette utilisation directe de produits humides demande davantage de manutention (produits pondéreux) et elle est surtout pertinente dans des contextes où la production animale est liée à celle de la ressource en termes de localisation et de calendrier de production.

Les ressources concernées sont, par exemple, les racines et tubercules (notamment le manioc), certaines feuilles fraîches (mûrier, manioc, fourrage de patate douce...), des drêches industrielles ou artisanales, etc. Elles contiennent typiquement 25 à $35 \%$ de MS (Buitrago 1990), soit en moyenne $700 \mathrm{~kg}$ d'eau par tonne de produit frais.

L'utilisation des ressources humides concerne principalement les ruminants et les porcins qui sont capables d'ingérer des volumes plus importants d'aliments que les volailles. Une importante question liée à l'usage de ces ressources est l'étude de la réponse des animaux à une ingestion d'eau importante dans l'aliment, en termes d'ingestion et de digestion, même si certaines connaissances ont été établies sur des pratiques existant dans les pays du Nord (alimentation des porcins en «soupe»).

\section{f) Utilisation de ressources énergé- tiques très faibles en protéines}

Dans les pays tropicaux, un certain nombre de ressources énergétiques ont une teneur faible voir nulle en protéines. Il s'agit par exemple des ressources amylacées comme les racines (manioc,
MAT $=2,5 \%$ ) (Base de données INRAAFZ) ou sucrées comme le jus de canne ou de palmier. L'utilisation de telles ressources augmente les exigences quantitatives et qualitatives en complémentation protéique, et modifie fortement le type de formulation par rapport aux standards basés sur des céréales contenant typiquement 9-12\% de protéines.

\section{g) Utilisation de ressources pro-} téiques riches en fibres

Certaines ressources protéiques disponibles dans les pays tropicaux ont une forte teneur en fibres. C'est par exemple le cas des tourteaux «pauvres» qui contiennent 50\% (coprah) à 66\% (palmiste) de NDF contre 15\% (palmiste) à $20 \%$ (coprah) de protéines (Tables INRA-AFZ, Sauvant et al 2004), ou des feuilles d'arbres ou des plantes herbacées.

Ces ressources sont complémentaires des aliments énergétiques faibles en protéines et en fibres (ex. manioc), mais la qualité et la digestibilité des protéines constituent souvent un facteur limitant conduisant à un fort besoin de complémentation par des protéines de meilleure qualité (ex. farines de poisson), ou à la limitation des taux d'incorporation notamment chez les monogastriques. Pour des systèmes peu intensifs ce sont cependant des sources alimentaires très intéressantes.

\section{2 / Variabilité liée aux traite- ments technologiques}

Les sous-produits de la transformation des ressources destinées à l'alimentation humaine constituent une source majeure de matières premières pour l'alimentation animale. Toutefois les traitements technologiques modifient les propriétés des produits et sont une source importante de variabilité de leur qualité. Nous illustrerons les conséquences des processus de transformation sur la variabilité des sous-produits par quelques exemples.

\section{a) Les tourteaux}

L'extraction d'huile proprement dite peut être précédée d'une préparation des matières premières destinée à faciliter le procédé d'extraction et/ou à valoriser le résidu (tourteau) par exemple le décorticage partiel ou total des graines. Ce point est particulièrement important pour des graines entourées par une coque ou une enveloppe fibreuse (coton, tournesol). Ces coques contiennent une très forte proportion de fibres et agissent donc comme une dilution de la partie nutritionnellement intéressante des tourteaux. 
La technologie d'extraction ellemême a un effet considérable sur la valeur nutritive des tourteaux. L'extraction artisanale, parfois réalisée au niveau familial avec des presses manuelles après broyage, malaxage et cuisson prolongée (ex. tourteau d'arachide) est aujourd'hui le plus souvent réalisée par de petites presses électriques. La matière grasse résiduelle est très variable : si les teneurs habituelles en $\mathrm{MG}$ des tourteaux expeller sont de l'ordre de 8 à $12 \%$, on trouve régulièrement des tourteaux mal extraits avec des teneurs de 15 voire $18 \%$ de MG.

L'extraction d'huile a pour effet de réduire l'énergie des graines et d'augmenter relativement les teneurs en MAT. Les trajectoires correspondantes sont typiques dans le cas de l'arachide, pour lequel le tourteau expeller est plus riche en énergie et un peu plus faible en MAT que le tourteau deshuilé. Dans le cas du coton, la baisse d'énergie n'est pas observée puisque l'extraction d'huile s'accompagne d'un décorticage qui retire une part significative des fibres.

D'autres coproduits de l'extraction d'huile sont disponibles. En premier lieu, les coques obtenues lors du décorticage. Les coques, toujours très fibreuses, ne peuvent être valorisées que par les ruminants. Leur valeur nutritive est très variable selon l'origine botanique : les coques de soja sont par exemple très digestibles, alors que celles d'arachide ou de tournesol ont une valeur énergétique extrêmement faible. Les coques de coton ont une valeur intermédiaire.
Chez ces matières premieres, les valeurs énergétiques sont corrélées au NDF indigestible.

Dans certains procédés d'extraction, une certaine quantité d'eau et de solides sont extraits en même temps que l'huile, et constituent les «boues d'extraction». Elles sont généralement peu valorisées mais peuvent être consommées fraîches par les ruminants voire les porcins, ou séchées. La valeur nutritive de ces boues séchées n'est pas connue précisément, mais des analyses réalisées au Tchad (boues d'extraction de l'arachide), où elles sont généralement brûlées, indiquent une composition chimique (MAT $>50 \%, \mathrm{MG}>15 \%)$ qui laisse envisager une valorisation intéressante (Bastianelli non publié).

\section{b) Les sous-produits de céréales}

$\mathrm{Si}$ la meunerie industrielle (blé notamment) est globalement comparable dans le monde entier, des différences majeures sont observées pour les coproduits artisanaux à cause des technologies employées et leur mise en œuvre.

\section{- Produits du maïs}

Les processus industriels de traitement du maïs proviennent de l'industrie amidonnière (process humide générant corn gluten feed et corn gluten meal, tourteaux de germes), de l'industrie de la distillation (process humide, générant des drèches (DDGS)), et de l'industrie de la semoulerie (process sec générant des sons et des tourteaux de germes). Les coproduits du maïs sont donc très différents selon la filière.

Figure 6. Variabilité des teneurs de fibres et d'amidon dans les coproduits du riz (Bastianelli non publié).

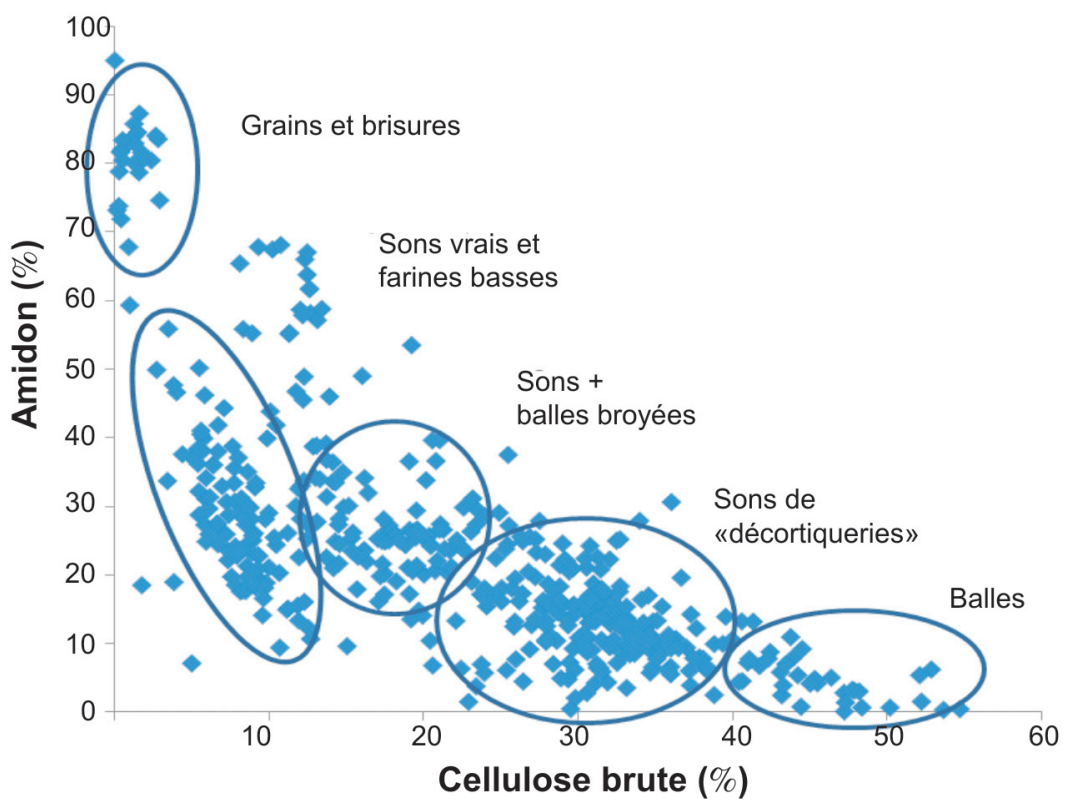

Des procédés de préparation du maïs destiné à l'alimentation humaine existent dans les pays du Sud. Ils peuvent varier depuis la préparation familiale, voire artisanale de petite ou de moyenne taille, et jusqu'à l'échelle industrielle (Amérique du Sud). Ces procédés peuvent différer, avec notamment une éventuelle opération d'humidification permettant un décorticage plus efficace, comme cela est pratiqué en Ouganda par exemple. Le son doit alors être séché avant d'être stocké, ce qui peut introduire une contamination par de la terre puisque le séchage est fait au sol. Dans d'autres pays, le décorticage se fait à sec, ou avec une humidification très légère avec de petits moulins électriques. Dans tous les cas, on arrive à des produits extrêmement variables notamment par leur teneur en fibres et en amidon, selon l'intensité de l'usinage des grains. La qualité du sous-produit est liée au rendement en matière de l'opération de décorticage, mais ce dernier est rarement connu.

\section{- Produits du riz}

Le riz est la céréale de base dans beaucoup de pays tropicaux. L'usinage du grain (blanchiment) qui produit le son est précédé par un décorticage permettant de retirer la balle, enveloppe fibreuse sans valeur nutritive. Le problème principal de qualité des sons de riz intervient lorsqu'une partie de la balle est introduite dans le son, par une mauvaise gestion du processus ou par fraude. On a alors un son de très faible valeur nutritive, parfois appelé son de «décortiquerie». Les différents sousproduits du riz se différencient par les teneurs en fibres, MAT et matières grasses. Par exemple, la figure 6 qui représente, pour 625 échantillons de sons de riz, la relation curvilinéaire entre la teneur en amidon et la teneur en cellulose brute illustre le gradient de qualité depuis les balles jusqu'aux farines basses. A l'intérieur de chaque catégorie la variabilité reste élevée (figure 6).

Les unités de décorticage artisanal de céréales ont parfois une activité parallèle de production d'aliments du bétail, qui valorise les sous-produits de l'activité de meunerie, comme c'était traditionnellement le cas pour les grands moulins industriels. Les aliments proposés par ces petits fabricants sont souvent formulés approximativement, et leur qualité est très variable. Ils s'adressent à une clientèle de petits éleveurs recherchant les aliments les moins chers possibles. Il arrive aussi que les «décortiqueurs» travaillent à façon, en usinant les céréales apportées par le client, et en étant payés pour ce travail directement, ou par tout ou partie de son produit. 


\section{c) Les farines de poisson}

Les farines de poisson représentent une source importante de protéines pour l'alimentation animale dans beaucoup de régions du Sud. Sous l'appellation «farines de poisson» de très nombreux produits se distinguent par : 1) La nature du «poisson»: déchets de l'industrie de découpe du poisson, écarts de triage ou poissons impropres à la consommation humaine, poissons pêchés spécifiquement pour l'alimentation animale, etc. ; 2) Le procédé de préparation et de séchage; 3) L'éventuelle extraction d'huile.

Les procédés industriels de préparation de la farine de poisson incluent généralement une cuisson (étuvage ou flux d'air chaud) et éventuellement un pressage avec récupération d'huile (qui constitue une autre ressource potentielle pour l'alimentation animale). Les procédés artisanaux sont variables, mais sont généralement réduits à un simple séchage. Celui-ci se fait au mieux sur des aires bétonnées, mais généralement à même le sol, induisant une contamination par de la terre ou du sable. On trouve ainsi dans certains cas des farines de poisson contenant plus de $70 \%$ de minéraux dont $60 \%$ de cendres insolubles dans l'acide. Le tableau 3 illustre la variabilité des farines de poisson artisanales en Afrique de l'Est. Les teneurs en protéines et en matières minérales sont extrêmement variables (CV de 32 et $43 \%$ respectivement). Les matières minérales sont fortement liées à leur fraction insoluble dans l'acide, c'est-àdire la contamination par des substances minérales exogènes, le carbonate du squelette étant soluble. Il y a une relation assez étroite entre MAT et MM, qui permet une première évaluation de la qualité du produit à l'aide d'une simple mesure des cendres. Un aspect intéressant est la bonne valeur des poissons vendus entiers : il s'agit de petites sardines du lac Victoria (Rastrineobola argentea) pêchées principalement pour l'alimentation animale. Ce produit est dans une certaine mesure une garantie de qualité puisque à part une dilution par des cendres insolubles dues au séchage, la valeur est proche de celle d'une farine de poisson industrielle de qualité moyenne («type 62»), avec même une teneur en MG - donc une valeur énergétique - supérieure.

\section{d) Facteurs antinutritionnels}

La présence de facteurs antinutritionnels (FANs) diminue la valeur nutritive de certaines matières premières, parfois dans des proportions importantes. Les FANs sont nombreux (inhibiteurs de protéases, lectines, tanins, composés cyanogéniques...), et certaines ressources comme les légumineuses et les oléagineux sont particulièrement concernées (Muzquiz et al 2004).

Les FANs peuvent également induire une forte variabilité de la valeur nutritive des ressources, à cause de teneurs variables selon les variétés cultivées (Nguz et Huyghebaert 1998, Cai et al 2010) ou les conditions de culture (Vollmann et al 2003) mais également par les traitements mis en place pour éliminer ces facteurs antinutritionnels.

Par exemple, Leon et al (1998) ont étudié l'influence des traitements technologiques sur la légumineuse Canavalia ensiformis. Des traitements thermiques ont permis de restaurer l'ingestion, déprimée chez le poulet par la présence de canavanine. Toutefois ces

Tableau 3. Composition (\%) de farines de poisson du Kenya et d'Ouganda, et comparaison avec les valeurs des Tables INRA-AFZ (Sauvant et al 2004).

\begin{tabular}{|c|c|c|c|c|}
\hline & MM & InsCl & MAT & MG \\
\hline Moyenne Générale $(n=91)$ & 37,0 & 15,1 & 49,8 & 10,9 \\
\hline Ecart type & 16,0 & 14,7 & 16,0 & 4,3 \\
\hline Minimum & 13,0 & 0,2 & 14,9 & 3,0 \\
\hline Maximum & 78,9 & 61,0 & 73,8 & 23,5 \\
\hline \multicolumn{5}{|l|}{ Composition par catégorie } \\
\hline $\begin{array}{l}\text { Poissons entiers }(n=35) \\
\text { (Rastrineobola argentea) }\end{array}$ & 24,5 & 8,6 & 61,8 & 12,0 \\
\hline Ecart type & 6,1 & 4,9 & 7,3 & 3,3 \\
\hline Poissons broyés $(n=56)$ & 44,6 & 19,0 & 42,6 & 10,2 \\
\hline Ecart type & 15,5 & 17,2 & 15,6 & 4,7 \\
\hline \multicolumn{5}{|l|}{ Valeurs Tables INRA-AFZ } \\
\hline Farine de poisson Type 62 & 22,1 & 0,3 & 66,4 & 9,8 \\
\hline Ecart type & 2,7 & 0,2 & 1,7 & 2,0 \\
\hline
\end{tabular}

MS : Matière sèche ; $\mathrm{MM}$ : Matières minérales ; InsCl : Insoluble Chlorhydrique ; MAT : Matières azotées totales ; MG : Matières grasses traitements ont eu une action négative sur la valeur énergétique des graines, avec une réduction de l'énergie métabolisable pouvant aller jusqu'à $34 \%(8,97$ contre 13,53 MJ/kgMS pour la graine crue) et de la digestibilité vraie de l'azote $(58,9$ contre $89,9 \%)$ pour les traitements les plus sévères $\left(190^{\circ} \mathrm{C}\right.$ pendant $24 \mathrm{~min})$. Les traitements plus légers permettent de trouver un optimum technique $\left(181^{\circ} \mathrm{C}, 13 \mathrm{~min}\right)$ mais tout écart génère soit une réduction de l'ingéré (traitement trop doux), soit une baisse de la valeur énergétique et azotée (traitement trop fort). Dans des conditions pratiques, la détoxification induit donc des variations importantes de la valeur nutritive. Le même type de problème est rencontré lors du traitement artisanal des graines de soja, qui peut réduire considérablement la digestibilité des protéines s'il est trop poussé.

\section{4 / Valorisation comparée des ressources par les espè- ces animales}

Toutes les ressources alimentaires ne sont pas utilisables par toutes les espèces animales avec la même efficacité. Les aliments riches en glucides solubles (amidons, sucres...) sont potentiellement utilisables par toutes les espèces animales d'élevage avec cependant des niveaux d'apport à ne pas dépasser chez les herbivores afin d'éviter les troubles digestifs. Les ressources les plus riches en fibres (plus de $35 \%$ de NDF) sont faiblement valorisées par les monogastriques non herbivores. Chez ces derniers, la présence de fibres pénalise à la fois l'apport d'énergie mais également la disponibilité des protéines. L'énergie, l'élément le plus coûteux des rations, est un facteur limitant fréquent des performances animales. Les flux d'énergie et de carbone étant étroitement corrélés, les bilans énergétiques sont pris en compte dans les évaluations environnementales. Les teneurs en fibres, élevées dans de nombreuses ressources tropicales, vont conditionner l'efficacité et les stratégies d'utilisation des sources d'énergie intra et inter-espèce animale.

Dans le contexte tropical, la concurrence Homme-animal d'élevage est exacerbée sur l'utilisation des protéines végétales les plus riches en Acides Aminés Essentiels (AAE). Par ailleurs, l'alimentation azotée des animaux est liée aux problèmes de pollution par excès de rejets azotés. Les proportions des rejets d'N alimentaire sont d'autant plus importantes que les animaux présentent de faibles niveaux de production et que le régime est de valeur nutritive azotée médiocre alors que ce sont des caractéristiques fréquentes dans le contexte tropical. 
Figure 7. Influence de la teneur en parois végétales sur la digestibilité de l'énergie des aliments en fonction des espèces animales (Sauvant et al 2004).

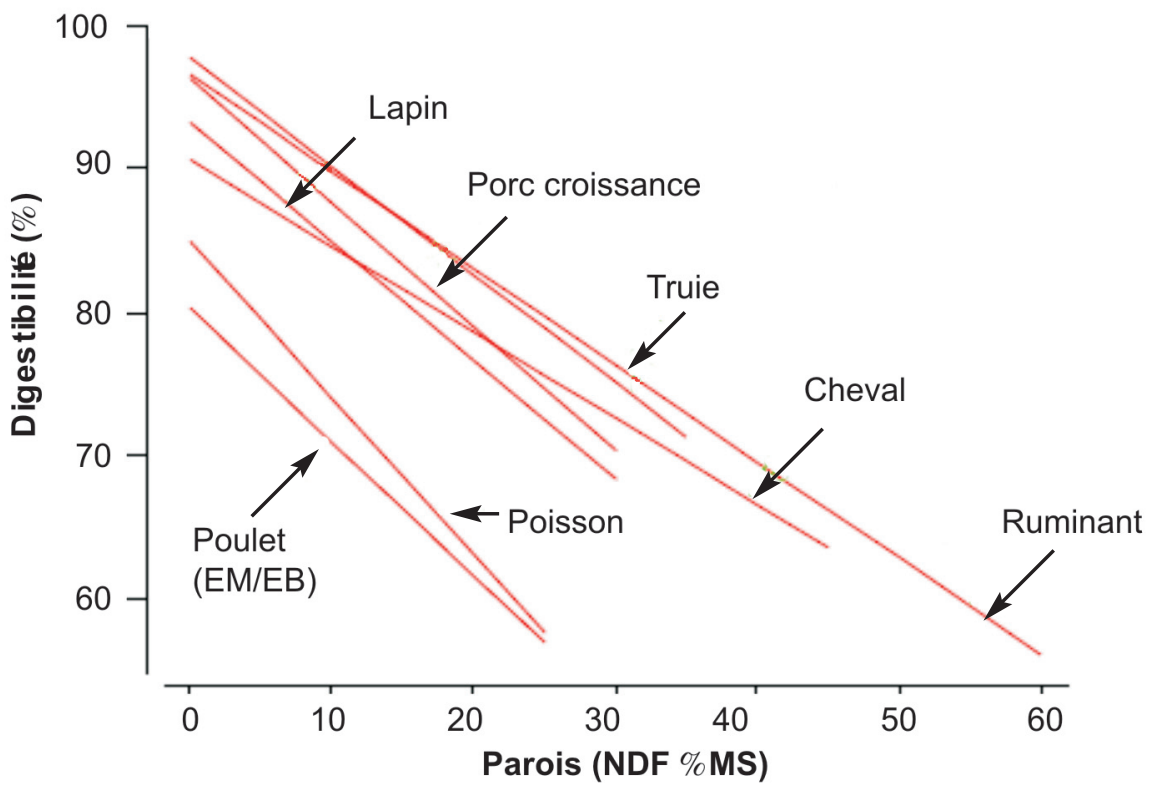

\section{1 / L'énergie}

a) Le rôle de la teneur en parois végétales

La digestibilité de l'énergie (dE), ou de la matière organique $(\mathrm{dMO})$ des ressources, est la principale cause de variation de l'efficacité de la transformation de l'énergie, ou du carbone, par les animaux. Cette efficacité résulte d'abord de celle de la digestion des parois végétales puisqu'il existe une relation étroite entre la digestibilité de la MO, ou de l'énergie, et la teneur d'un régime en constituants pariétaux non digestibles (figure 7). La lente et difficile (taux de 2 à $6 \% / \mathrm{h})$, et de ce fait plus ou moins incomplète, digestion des parois végétales explique cette dernière relation. Elle est dépendante de la digestion microbienne puisque les êtres vivants supérieurs ne synthétisent pas d'enzymes aptes à dégrader les parois végétales. La durée du transit digestif influence aussi la capacité digestive des animaux notamment au sein des zones de stase où les écosystèmes digestifs utiles peuvent se développer. Parmi les herbivores, les lapins apparaissent comme de mauvais digesteurs des parois en raison d'un transit trop rapide du bol alimentaire, sachant que la cæcotrophie ne compense que partiellement ce handicap.

Les microorganismes des écosystèmes digestifs ont donc un rôle essentiel vis à vis de la valorisation des constituants pariétaux mais leur activité s'accompagne d'une perte de substrats carbonés sous forme de $\mathrm{CO}_{2}$ et surtout de $\mathrm{CH}_{4}$. Ce dernier gaz étant très riche en énergie, cela explique que l'efficacité du ruminant par rapport aux monogastriques, porcs et volailles en particulier diminue à l'étape du passage de l'énergie digestible à l'énergie métabolisable.

Les différentes espèces animales n'ont pas la même aptitude à extraire de l'Energie Métabolisable (EM) des ressources végétales ingérées. Il y a par ailleurs des différences intra-espèce en fonction du stade physiologique. Par exemple, les porcs adultes tirent un meilleur profit (de 5 à $15 \%$ d'EM) des matières premières riches en parois végétales que les porcs en croissance, en raison d'un tube digestif distal plus développé.

Des interactions existent entre les espèces animales dans la hiérarchie pour la valorisation de l'EM en fonction de la teneur en énergie de l'aliment.

Pour être plus précis dans la hiérarchisation des valorisations énergétiques des ressources par les animaux, l'idéal serait de pouvoir raisonner en Energie Nette (EN). Malheureusement, pour des raisons de coût des investigations, ces mesures n'ont pas été effectuées de façon suffisamment systématique pour pouvoir disposer de systèmes d'unités d'EN pour les différentes espèces animales.

\section{b) Le rôle de la nature des parois végétales}

Pour les aliments non fourragers, mais riches en constituants pariétaux, il importe de préciser la nature de ces constituants. En effet, lorsqu'il s'agit de tissus végétaux qui n'ont pas de rôle de soutien (racines...), ou pour certains genres (zea...) ou familles (palmiers...), les tissus contiennent peu de parties lignifiées et ils possèdent, de ce fait, des parois facilement digestibles. Par exemple, on trouve parmi ces ressources les sous-produits du maïs grain, les tourteaux de coprah et de palmiste, les pulpes d'agrumes et de betteraves, les coques de soja. Au sein de ce groupe de ressources la digestibilité diminue de 0,88 point par point de NDF (Sauvant $e t$ al 2004). A l'opposé, d'autres ressources telles que les enveloppes de céréales autres que le maïs grain, les parois végétales des graines de tournesol, ont des parois peu digestibles. Au sein de ce groupe de ressources la digestibilité diminue de 0,35 par point de NDF (Sauvant et al 2004).

Ces différences entre types de parois végétales ne seront pas neutres vis à vis de la concurrence entre valorisation par les animaux et valorisation non agricole des ressources riches en parois végétales. L'animal gardera un pouvoir de concurrence plus marqué pour les aliments à parois digestibles.

\section{2 / L'azote}

Il convient de considérer différemment les efficacités digestives et métaboliques qui correspondent à des phénomènes biologiques et des facteurs de variation très différents. Les deux principaux facteurs de variation de digestibilité de la MAT sont la teneur en parois végétales, qui l'affecte négativement alors que la teneur en MAT du régime l'influence positivement. Les métabolites secondaires (facteurs antinutritionnels, tanins...) interfèrent aussi sur la digestibilité des protéines alimentaires.

Au-delà de la digestion, l'efficacité métabolique des protéines digérées dépend étroitement de leur équilibre en acides aminés. Sous l'angle des AA, comme celui de l'énergie, il convient de faire une distinction nette entre animaux monogastriques et ruminants.

Il est nécessaire, chez les monogastriques, d'apporter des régimes qui contiennent une concentration suffisante en AAE. La plupart des AA, exception faite de la lysine, sont présents dans de nombreuses matières premières peu concurrentielles de l'homme. La lysine n'est en concentration importante que dans le soja d'où le rôle stratégique de cette ressource azotée. Le profil d'AA disponibles ne peut être assimilé à celui présent dans la matière première. Pour se rapprocher au mieux des besoins et être plus précis dans la valorisation des ressources protéiques, des mesures de digestibilité ont été pratiquées chez les 
porcs et les volailles de manière à pouvoir formuler en acides aminés digestibles. Cependant, il manque des données sur de nombreuses ressources protéiques des régions chaudes.

Chez les ruminants, les microbes de la panse, qui contribuent au pool d'acides aminés sont très riches en AAE dont la lysine. Ces microorganismes sont en outre capables de synthétiser leurs propres protéines à partir de sources azotées non aminées. Les acides aminés microbiens permettent de couvrir en moyenne les $2 / 3$ des besoins protéiques des ruminants. Dans ce contexte, pour les niveaux de production moyens, la qualité des protéines alimentaires ingérées n'est pas un facteur limitant. Avec des rations pauvres en azote (moins de $12 \%$ ), fréquentes en zone tropicale, les ruminants sont capables de recycler des quantités importantes d'urée dans le rumen pour produire de la protéine microbienne, jusqu'à $50 \mathrm{~g}$ de protéines par kg de MS ingérée. En conséquence, la quantité totale de protéines (microbiennes et alimentaires) arrivant dans l'intestin est supérieure aux protéines ingérées d'où un bilan protéique du rumen positif (protéines arrivant dans l'intestin-protéines ingérées) (figure 8). Au-delà d'une teneur en MAT de $12 \%$ environ, ce bilan devient négatif suite à un moindre recyclage de l'urée dans le rumen, des pertes croissantes d'azote via l'absorption d'NH3 et leur élimination par la voie urinaire. Dans ce cas, il y a un gâchis azoté par la voie urinaire qui va croissant à mesure de l'augmentation de la teneur en MAT du régime.

Les graminées tropicales sont de teneur variable en AA mais souvent inférieure à $12 \%$ de la MS ingérée. La valorisation de la grande majorité de ces fourrages dépend beaucoup de l'efficacité du recyclage d'urée salivaire. Pour les animaux à haut niveau de production, présents dans certains systèmes d'élevage, la protéosynthèse microbienne peut être insuffisante pour couvrir les besoins totaux en protéines. Il est alors nécessaire de fournir des protéines protégées de la dégradation microbienne et bien équilibrées en AA. Certaines matières premières tropicales riches en tanins sont a priori intéressantes dans ce contexte, à condition qu'elles soient bien équilibrées en AA et facilement digestibles dans l'intestin grêle. Cette dernière condition serait réunie pour des teneurs en tanins n'excédant pas 2-3\% (Makkar 2003, Waghorn 2008). Ce plafond reste cependant à préciser; il y a en effet peu de travaux sur les ressources tropicales alors qu'une variabilité existe en fonction de la nature des tanins.

Chez les monogastriques, le porc en particulier, les ressources fibreuses ont
Figure 8. Bilan protéique (protéines arrivant dans l'intestin - protéines ingérées) du rumen en fonction de la teneur en MAT du régime des bovins (Sauvant non publié).

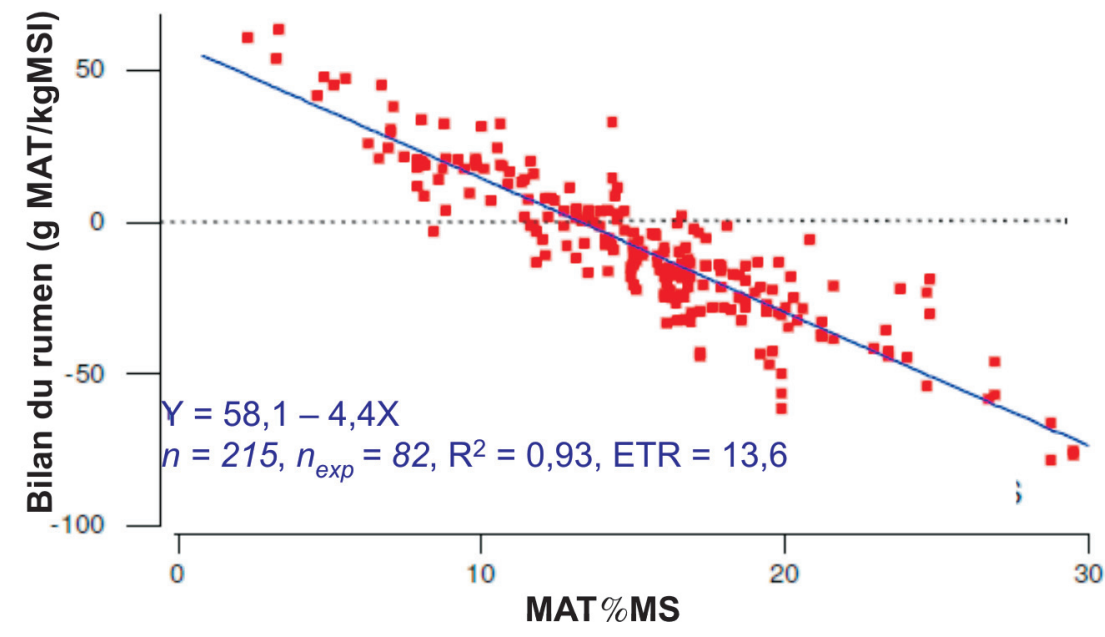

de faibles valeurs alimentaires qui s'expliquent par une dilution des protéines et de l'énergie brute par des matières minérales (9 à 15\%) et les fibres (NDF : 38 à $54 \%$ ) présentes en grande quantité dans les feuilles et par le fait que ces protéines ou cette énergie est faiblement digestible pour le porc. Cette faible digestibilité s'explique d'abord par une forte teneur en fibres mais également par la présence en quantité non négligeable de facteurs antinutritionnels (polyphénols et tanins condensés). Ces composés secondaires ont un effet important sur l'ingestibilité des feuillages tropicaux par les porcs (Régnier 2011).

Ces différentes particularités montrent que les ruminants occupent une place particulière, non concurrentielle de l'Homme, dans la chaine alimentaire protéique.

\section{5 / Discussion et conclusions}

Nous avons illustré une grande diversité et une large variabilité de la VA des ressources alimentaires tropicales. En intra-ressource la variabilité semble plus élevée que celle indiquée pour les ressources de la zone tempérée. Cela tient probablement à plusieurs phénomènes. La gestion des ressources, identifiée comme un important facteur de variation, est moins homogène que celle rencontrée en zone tempérée, reflétant ainsi la grande diversité au sein des exploitations agricoles. Par ailleurs, les conditions de milieu peuvent être très hétérogènes au sein de la zone tropicale. De nombreuses ressources n'ont pas fait l'objet de sélection génétique ce qui contribue à la variabilité observée. De plus, la physiologie en $\mathrm{C} 4$ des graminées tropicales entraîne une évolution rapide de la composition des fourrages. Pour ce qui relève des coproduits de l'agro-industrie, la présence de nombreuses structures de type artisanale crée de la variabilité plus importante que celle issue des chaînes industrielles relativement standardisées des pays du Nord.

Bien que variables, les données de VA reportées par la bibliographie indiquent qu'il y a une large offre de ressources permettant de soutenir de forts niveaux de productivité des élevages. Ces ressources ont aussi des disponibilités, présentes et à venir, variables. La concurrence entre l'Homme et l'animal pour l'utilisation de certaines ressources (céréales, tubercules, pois...) existe aussi. Cette concurrence ne se limite pas à la seule utilisation de la ressource, il y a aussi celle de l'occupation des surfaces agricoles. Quelle que soit la ressource, toute surface utilisée pour produire des aliments pour l'animal est une surface en moins disponible pour des cultures vivrières et industrielles. Dans un tel contexte, les cultures dont la biomasse peut être utilisée intégralement, suite à l'Homme et de l'animal, sont des atouts. Ainsi, l'intérêt pour les coproduits fibreux des principales productions vivrières (pailles des céréales, feuillages de tubercules, bananiers...), les coproduits de certaines plantes industrielles (canne à sucre, coton...), les coproduits de l'agro-industrie (tourteaux, sons...), devrait augmenter dans les années à venir. Ce constat plaide pour la prise en compte de la VA de ces coproduits dans la sélection parallèlement à la production et la qualité des aliments pour l'Homme. L'utilisation massive des coproduits comme aliment pourrait entraîner des transferts de matière organique entre territoires. Ces transferts pourraient être réduits par une plus grande intégration entre les cultures et les productions animales. De même, la lutte contre le réchauffement climatique et la recherche de puits de carbone un fractionnement pour les usages des 
devraient augmenter l'intérêt pour les systèmes agroforestiers et les ressources associées (arbres fourragers). Plus largement, l'évaluation des ressources devraient intégrer le critère environnemental à coté de la VA.

La très grande diversité des ressources alimentaires et des facteurs de variation de leur valorisation par les animaux d'élevage, constituent des leviers de progrès pour atteindre une bonne adéquation entre la demande alimentaire des hommes et une gestion adaptée et durable des ressources. Les quelques exemples présentés de la recherche actuelle, qui anticipent les applications futures, vont dans ce sens. Ainsi le gisement des ressources naturelles ou cultivées, est de mieux en mieux connu, quantitativement et qualitativement. Certaines modalités de traitement des ressources et de gestion des pâturages permettent d'atteindre une productivité élevée. En outre, on connaît de mieux en mieux les niveaux de valorisation comparée de mêmes ressources par des espèces animales différentes. La disponibilité des ressources est moindre pour les monogastriques, comparativement aux polygastriques. Chez le porc par exemple, outre les fortes teneurs en eau quand les rations sont distribuées sous forme fraîche, les matières premières tropicales sont généralement riches en énergie et/ou en fibres et le plus souvent sont pauvres en protéines. Or, dans les systèmes de production rencontrés dans les régions tropicales, un des premiers facteurs limitant est l'approvisionnement en protéines. Les protéagineux sont peu utilisés car ils entrent directement en concurrence avec l'alimentation humaine. Les feuillages tropicaux, alternatifs au soja, ont en moyenne des valeurs énergétiques (base $\mathrm{EM}, \mathrm{MJ} / \mathrm{kg}$ MS) et protéique (base lysine digestible vraie, $\mathrm{g} / \mathrm{kg} \mathrm{MS}$ ) représentant respectivement 45 et $20 \%$ de celles du tourteau de soja (Regnier 2011).

De nombreuses études permettent de disposer d'un important gisement d'informations, sur la productivité, la composition et la VA des ressources. Cependant, les valeurs de digestibilité et d'ingestibilité des ressources sont rares relativement à celles portant sur les compositions chimiques. Par ailleurs, l'accessibilité à ces multiples données demeure limitée (revues locales, dispersion extrême des travaux...). En outre, les travaux ont été réalisés dans des contextes particuliers, ils sont souvent partiels, et présentent rarement une valeur universelle (à titre d'exemple, les situations des régions sèches, à effets saisonniers très marqués, diffèrent beaucoup de celles des régions plus humides). De ce fait, l'extrapolation des données d'un contexte à l'autre est sou- vent délicate, notamment en ce qui concerne l'effet des facteurs de variation (âge des plantes, climat...). Il est essentiel de rassembler ces données, de les mettre en cohérence et de hiérarchiser les facteurs de variation pour produire des connaissances à la fois globales et précises des ressources alimentaires mondiales. La puissance des outils de traitement des informations et d'analyse devrait permettre d'atteindre ces objectifs. Ce travail de compilation et d'analyse plus globale pourrait être facilité par le projet «AFZ-INRA-CIRAD» de réalisation de tables alimentaires en régions chaudes et la mise en place de réseaux de recherches associant les équipes de recherches travaillant dans le Nord et dans le Sud. En plus du partage d'expériences pour l'étude des ressources, il convient de développer des approches en positionnant certaines ressources d'intérêt comme des modèles biologiques. L'association des ressources tempérées et tropicales dans les bases de données permet de tester les grandes lois de la zootechnie du fait de l'élargissement des gammes de variations des caractéristiques des ressources.

Les priorités de recherche sont à différencier en fonction des systèmes de production. Certaines ressources sont sous-exploitées, soit parce qu'elles sont mal connues ou ignorées, soit parce que leur utilisation n'est valable que dans un contexte donné. Il est important de caractériser les ressources en proposant des méthodes d'évaluation pragmatiques, adaptées aux niveaux d'intensification auxquels on s'adresse. A titre d'illustration, la connaissance de la digestibilité des acides aminés n'est pas forcément indispensable pour la valorisation d'une ressource locale dans un système de production villageois très peu intensif, alors qu'elle est indispensable dans la perspective d'une utilisation industrielle d'une ressource alternative aux ressources «classiques». Les informations sur les éventuels facteurs antinutritionnels sont en revanche importantes dans la plupart des contextes.

Comme en zone tempérée, la recherche de ressources protéiques alternatives au soja est une question stratégique. Il semble important de continuer de produire de la connaissance sur ce volet en puisant dans la biodiversité locale et mettant au point des modes de gestion (agronomique, et technologique) identifiés comme facteurs de variation majeurs. Du fait de la présence de composés antinutritionnels dans ces ressources, les seules valeurs de composition chimiques classiques permettent difficilement de prévoir les valeurs alimentaires.
L'évaluation des ressources conduira à développer les connaissances sur certains métabolites secondaires des plantes dont la présence est souvent une adaptation au milieu. Plutôt que de les éliminer, la bonne stratégie serait de mieux les connaître pour les gérer. Les études sur la présence de métabolites secondaires (tanins hydrolysables et condensés, saponines...) dans des végétaux, ainsi que les facteurs de variation font défaut bien que différentes synthèses aient déjà été écrites sur ce sujet (Makkar 2003, Waghorn 2008, Beauchemin et al 2009). Cependant, des limites de type méthodologiques liées entre autres au dosage quantitatif des molécules actives ainsi que leur caractérisation fine persistent. Cela explique la grande variabilité pouvant exister intra-ressource. De même, des connaissances sont à acquérir sur les seuils associés aux effets positifs et négatifs que peuvent avoir ces métabolites sur les différentes fonctions de l'animal. Les métabolites secondaires peuvent impacter positivement ou négativement l'alimentation, la reproduction, la santé et la production (lait, viande) des animaux (Rochefort et al 2008). D'autres questions persistent telles que la prévision des effets du changement climatique sur la disponibilité spatiale des ressources. Enfin, les interactions aliment-animal représentent aussi un champ important de recherche. Les caractéristiques physico-chimiques des nouveaux aliments, plus étendues que celles classiquement étudiées, pourraient impacter certaines régulations physiologiques de l'animal.

Au-delà de la valeur nutritive, l'étude des modes d'alimentation sera importante. Ainsi, dans des contextes de production de monogastriques à petite échelle, des systèmes basés sur des ressources pondéreuses (diluées en eau, en fibres) produites localement peuvent être pertinents, alors qu'ils ne le sont pas pour de grandes productions industrielles. La proximité des zones de production de ces ressources et celles des élevages est souvent une condition indispensable à leur rentabilité économique. Ce type de pratiques à base d'aliments pondéreux nécessite des études notamment sur la capacité d'ingestion des animaux, assez mal connue dès que l'on s'éloigne des régimes classiques concentrés en énergie. Des transformations (séchage, ensilage, broyage...) de ces aliments pondéreux peuvent permettre une meilleure utilisation et conservation, mais il convient d'en évaluer les coûts énergétiques.

Au cours des prochaines décennies, le développement des productions animales va constituer un enjeu majeur pour la sécurité alimentaire mondiale. Face à 
cela, de grosses incertitudes demeurent sur les prévisions du climat, de la situation économique et énergétique (politiques et pratiques d'aménagement des territoires, concurrence des biocarburants...), la démographie des populations humaines, etc. Cependant, au-delà de ces incertitudes il importe de préciser les offres en ressources et l'adéquation ressources-productions animales. Des progrès ont été réalisés dans ce domaine en matière d'aménagement du territoire et certaines actions en cours, telles que la prospective "Agrimonde» (INRA 2009), devraient aboutir à un meilleur diagnostic et à des propositions plus réalistes et précises.

Les productions animales ont été critiquées à cause de leurs contributions à la dégradation de la qualité de l'environnement, à certaines crises sanitaires... Sans négliger ces impacts négatifs, il convient aussi de «positiver» l'image de l'élevage en soulignant les atouts des productions animales au sein d'approches multifonctionnelles : servi- ces écosystémiques et sociétaux de l'élevage : gestion de l'espace et de la biodiversité, fertilité des sols (matière organique...), systèmes agroforestiers, etc. La «pos-ture» de la recherche est en cours d'évolution dans ce sens. Ainsi le concept de lois de réponses multiples aux pratiques alimentaires, appliqué au niveau de l'animal, du troupeau ou du système de production, est pris en compte dans la plupart des travaux.

L'intensification des itinéraires techniques des productions animales est avant tout basée sur la maximisation de la fonction de production des animaux et la formulation de rations permettant de soutenir cette productivité. De fait, seuls des critères strictement liés à l'efficience nutritionnelle des ressources végétales sont pris en compte pour les rendre ou non éligibles comme aliment. Les ressources les plus encombrants, les moins denses en termes nutritionnels sont exclues. L'intensification écologique devrait s'inscrire dans une logique différente : «l'agriculture d'abord». Ainsi, la préoccupation première est, dans un contexte de réduction des intrants, de maximiser la production de biomasse et d'optimiser son utilisation entre différents usages dont l'alimentation d'animaux, qui tout comme les cultures seront évalués sur plusieurs fonctions. En conséquence, les ressources alimentaires seront appréciées aux travers de lois de réponses multiples des animaux (production, émissions métaboliques et digestives...), qui doivent être optimisées. Il conviendra, par ailleurs, d'intégrer que plusieurs aliments sont souvent associés au sein d'une ration. L'intensification écologique peut passer par la mise au point de systèmes d'élevage qui ne maximisent pas uniquement la production, mais un facteur d'efficience multicritère intégrant des paramètres économiques, environnementaux (GES, énergie), sociaux, etc. Des efforts de modélisation doivent être entrepris pour proposer des lois de réponse à ces conditions.

\section{Références}

Archimède H., Poncet C., Boval M., Nipeau F., Philibert L., Xandé A., Aumont G., 1999. Comparative intake and digestion of fresh or dry grass of Digitaria decumbens consumed by Black-belly sheep. J. Agric. Sci., 133, 235-240.

Assoumaya C., Sauvant D., Archimède H., 2007. Etude comparative de l'ingestion et de la digestion des fourrages tropicaux et tempérés. INRA Prod. Anim., 20, 383-392.

Aumont G., Caudron I., Saminadin G. Xandé A., 1995. Sources of variation in nutritive values of tropical forages from the Caribbean. Anim. Feed Sci. Technol., 51, 1-13.

Beauchemin K.A., McAllister T.A., McGinn S.M., 2009. Dietary mitigation of enteric methane from cattle. $\mathrm{CAB}$ Reviews: Perspectives in Agriculture. Vet. Sci., Nutr Nat. Res., 4, 1-18.

Boval M., 2008. L'alimentation au pâturage des ruminants en zone tropicale, méthodologies, facteurs de variation et déterminisme. Rapport HDR, 55p.

Boval M., Cruz P., Peyraud J.L., Penning P., 2000. The effect of herbage allowance on daily intake by Creole heifers tethered on natura Dichanthium spp. pasture. Grass Forage Sci., 55, 201-208

Boval M., Archimède H., Tournebize R., Coppry O., 2002a. Stage of regrowth of tropical forage have various effect on diet quality of grazing heifers. In: Multi-function grasslands: quality forages, animal products and landscapes. Proc. $19^{\text {th }}$ Gen. Meet. Eur. Grassland Fed., 2730 May, La Rochelle, France, 108-109.

Boval M., Cruz P., Ledet J.E., Coppry O., Archimede H., 2002b. Effect of nitrogen on intake and digestibility of a tropical grass grazed by Creole heifers. J. Agric. Sci., 138, 73-84.

Boval M., Fanchone A., Archimède H., Gibb M.J., 2007. Effect of structure of a tropical pasture on ingestive behaviour, digestibility of diet and daily intake by grazing cattle. Grass Forage Sci., 62, 44-54

Buitrago A., 1990. La Yuca en la alimentacion animal. Centro Internacional de Agricultura Tropical. CIAT, 446p.

Cai Y., Xie Y., Liu J., .2010. Glandless seed and glanded plant research in cotton. A review. Agron. Sustain. Dev., 30, 10.

Chanda G., Bhunia G., Chakraborty S., 2010. Evaluation of nutrient status of different organic wastes along with environmental quality in the different phases of vermicomposting by Perionyx excavatus Perrier. Manag. Env. Quality, 21, 368-378.

Chenost M., Kayouli C., 1997.Roughage utilization in warm climates. FAO Anim. Prod. Health Paper, 135.

Cruz P., Boval M., 2000. Effect of nitrogen on some morphogenetic traits of temperate and tropical perennial forage grasses. In Grassland ecophysiology and grazing ecology. Lemaire G. Hodgson J., De Moraes A., Carvalho P.C. Nabinger C. (Eds). University of Cambrigde, UK, 151-168

Delgado C., Rosegrant M., Steinfeld H., Ehu, S., Courbois C., 1999. Livestock to 2020 the next food revolution. Food Agric. Env. Discussion, Paper 28, 73p

FAO, 2009. La situation mondiale de l'alimentation et de l'agriculture. Rome, Italie, 186p.

Fanchone A., Archimède H., Baumont R. Boval M., 2010. Intake and digestibility of fresh grass fed to sheep indoors or at pasture, at two herbage allowances. Anim. Feed Sci Technol., 157, 151-158.

Foley W.J., Iason G.R., McArthur C., 1999 Transdisciplinary studies of plants secondary metabolites: lessons from ecology for anima science and vice versa. Proc. Fifth Int. Symp.
Nutr. Herbology, Am. Soc. Anim. Sci., Illinois, USA, 130-209

Guérin H., 1999. Valeur alimentaire des fourrages cultivés. In : Cultures fourragères tropicales. Roberge G., Toutain B. (Eds). CIRAD, Montpellier, France, 93-145.

Herrero M., Thornton P.K., Notenbaert A.M., Wood S., Msangi S., Freeman H.A., Bossio D., Dixon J., Peters M., van de Steeg J., Lynam J., Parthasarathy Rao P., Macmillan S., Gerard B., McDermott J., Seré C., Rosegran M., 2010. Smart investments in sustainable food production: revisiting mixed crop-livestock systems. Science, 327, 822-825.

Humphreys L.R., 1991. Tropical pasture utilisation. Cambridge University Press, USA, $220 \mathrm{p}$

INRA, 2009. Agricultures et alimentations du monde en 2050 : scénarios et défis pour un développement durable. www.inra.fr/1 institut/prospective/prospective agrimonde

Leng RA., 1997. Tree foliage in ruminant nutrition. FAO Anim. Prod. Health Paper, 139.

Leon, A., Vargas R., Michelangeli C. Melcion J., Picard M., 1998, Detoxification of jackbean (Canavalia ensiformis L.) with pilot scale roasting. II. Nutritional value for poultry. Anim. Feed Sci. Technol., 73, 231-242.

Leterme P., Botero M., London A.M. Bindelle J., Buldgen A., 2006. Nutritive value of tropical tree leaf meals in adult sows. Anim. Sci., 82, 175-182.

Machin D., Nyvold S., 1992. Roots, tubers, plantains and bananas in animal feeding. FAO Anim. Prod. Health Paper, 95.

Makkar H.P.S, 2003, Review. Effects and fate of tannins in ruminant animals, adaptation to tannins, and strategies to overcome detrimental effects of feeding tannin-rich feeds Small Rum. Res., 49, 241-256. 
Mears P.T., Humphreys L.R., 1974. Nitrogen response and stocking rate of pennisetum-clandestinum pastures .1. Pasture nitrogen requirement and concentration, distribution of drymatter and botanical composition. J. Agric. Sci., 83, 451-467.

Mekbungwan A., 2007. Application of tropical legumes for pig feed. Anim. Sci. J., 78, 342-350.

Nelson C.J., Burns, J.C., 2006. Fifty years of grassland science leading to change. Crop Sci., 46, 2204-2217.

Meyer C., Denis J.P., 1999. Elevage de la vache laitière en zone tropicale. Ed. CIRAD, Montpellier, France, 313p.

Minson D.J., 1990. Forage in ruminant nutrition. Academic Press, Inc San Diego, California, USA, 483p.

Muzquiz M., Hill G., Burbano C., Cuadrado C., Pedrosa M., 2004. Recent advances of research in antinutritional factors in legume seeds and oilseeds. EAAP Publication, 110,384p.

Nguz K., Huyghebaert A., 1998. Effect of tannins concentration on in vitro protein digestibility of some African sorghum [Sorghum bicolor (L. Moench)] varieties. Sci. Alim., 18, 293-300.

Patra A.K., 2008. A meta-analysis on effects of supplementing low-quality roughages with foliages from browses and tree fodders on intake and growth in sheep. Livest. Sci., 121, 239-249.

Patra A.K., 2009. Effects of supplementing low-quality roughages with tree foliages on digestibility, nitrogen utilization and rumen characteristics in sheep: a meta-analysis. J. Anim. Physiol. Anim. Nutr., 94, 338-353.

Pérez R., 1997. Feeding pigs in the tropics. FAO Anim. Prod. Health Paper, 132.

Preston T.R., 1995. Tropical animal feeding. FAO Anim. Prod. Health Paper, 126.

Preston T.R., 2006. Forages as protein sources for pigs in the tropics. Workshop-seminar Forages for Pigs and Rabbits. MEKARNCelAgrid, 22-24 August, 2006. Retrieved, December 19, Phnom Penh, Cambodia, 110, http://www.mekarn.org/proprf/preston.htm.
Preston T.R., 2009. Environmentally sustainable production of food, feed and fuel from natural resources in the tropics. Trop. Anim. Health Prod., 41, 873-882.

Régnier C., 2011. Valorisation des ressources alimentaires tropicales (feuillages et tubercules) chez le porc. Thèse de doctorat, Université des Antilles et de la Guyane, 203p.

Rodríguez L., Peniche I., Preston T.R., Peters K., 2009. Nutritive value for pigs of New Cocoyam (Xanthosoma sagittifolium); digestibility and nitrogen balance with different proportions of fresh leaves and soybean meal in a basal diet of sugar cane juice. Livest. Res, for Rur. Dev., 21, Article 16 http://www.lrrd.org/lrrd21/1/rodr21016.htm

Roberge G., Toutain B., 1999. Cultures fourragères tropicales. Coll. Repères, Editions Quae, Paris, France, 369p.

Rochefort S., Parker A.J., Dunshea F.R 2008. Plant bioactives for ruminant health and productivity. Phytochemistry, 69, 299-322.

Sarnklong C., Cone J.W., Pellikaan W. Hendriks W.H., 2010. Utilization of rice straw and different treatments to improve its feed value for ruminants: a review. Asian-Austr. J. Anim. Sci., 23, 680-692.

Sauvant D., Perez J.M., Tran G., 2004. Tables de composition et de valeur nutritive des matières premières destinées aux animaux d'élevage : porcs, volailles, bovins, ovins, caprins, lapins, chevaux, poissons. 2 ème Edition revue et corrigée. INRA Editions, Paris, France, 301p.

Seré C., Steinfeld H., 1996. World livestock production systems: current status, issues and trends. Anim. Prod. Health Paper, 127, 82p.

Schiere J.B., Joshi A.L., Seetharms A Oodting S. J., Goochilds A. V., Deinum B., Van Keulen H., 2004. Review paper. Grain and straw for whole plant value: implications for crop management and genetic improvement strategies. Expl. Agric., 40, 277-294.

Steinfeld H., Gerber P., Wassenaar T., Castel V., Rosales M., de Haan C., 2006. Livestock's long shadow: Env. Issues Options. FAO, Rome, Italie, 390p.

Sotomayor-Rios A., Pitman W.D., 2001

Tropical forage plants: development and use.
CRC Press LLC, 2000 N.W. Corporate Blvd. Boca Raton, USA. Hardback, 391p.

Speedy A., Pugliese P., 1991. Legume trees and other fodder trees as protein sources for livestock. FAO Anim. Prod. Health Paper, 102.

Thornton P.K., Van de Steeg J., Notenbaert A., Herrero M., 2009. The impacts of climate change on livestock and livestock systems in developing countries: A review of what we know and what we need to know. Agric. Syst., 101, 113-127.

Tiemann T.T., Lascano C.E., Wettstein H.R., Mayer A.C., Kreuzer M., Hess D., Zurich E.T.H., 2008. Effect of the tropical tannin-rich shrub legumes Calliandra calothyrsus and Flemingia macrophylla on methane emission and nitrogen and energy balance in growing lambs. Animal, 2, 790-799.

Van Soest P.J., 2006. Review. Rice straw, the role of silica and treatments to improve quality. Anim. Feed Sci. Technol., 130, 137-171.

Vollmann J., Grausgruber H., Wagentristl H., Wohleser H., Michele P., 2003. Trypsin inhibitor activity of soybean as affected by genotype and fertilisation. J. Sci. Food Agric., $83,1581-1586$.

Waghorn G., 2008. Beneficial and detrimental effects of dietary condensed tannins for sustainable sheep and goat production. Progress and challenges. Anim. Feed Sci. Technol., 147, 116139.

Wanapat M., 2009. Potential uses of local feed resources for ruminants. Trop. Anim. Health Prod., 41, 1035-1049.

Wilson J.R., 1994. Cell wall characteristics in relation to forage digestion by ruminants. $J$. Agric. Sci., 122, 173-182.

Wilson T.R., 2009. Fit for purpose, the right animal in the right place. Trop. Anim. Health Prod., 41, 1081-1090.

Xandé A., Garcia-Trujillo R., Caceres O., 1989. Feeds of humids tropics (West Indies). In: Ruminant nutrition. Recommended allowances and feed tables. Jarrige R. (Ed). INRA, Versailles, France, 347-363.

Zemmelink G., Mannetje L., 2002. Value for animal production (VAP): a new criterion for tropical forage evaluation. Anim. Feed Sci. Technol., 96, 31-42.

\section{Résumé}

La disponibilité et les facteurs de variation de la valeur alimentaire des ressources végétales tropicales et des sous-produits de l'agroindustrie sont présentés dans cette synthèse. Les ressources alimentaires utilisées sont très variées (herbes, arbres fourragers, céréales, tubercules, coproduits de culture, sous-produits de l'agro-industrie) à l'image de la grande diversité des systèmes de production plus ou moins intensifiés, avec un niveau d'intégration variable des cultures et de l'élevage. Les matières premières peuvent être identiques à celles utilisées dans les zones tempérées (soja, maïs), notamment dans les ateliers modernes. Elles peuvent aussi se singulariser par leur origine botanique (sorgho, tubercules, fourrages, arbres fourragers), leur composition (présence fréquente de métabolites secondaires) et les traitements technologiques (coproduits d'industries agroalimentaires artisanales) qu'elles ont pu subir. Il y a une grande variabilité de la valeur alimentaire intra et inter-ressources. Quelle que soit l'espèce animale considérée, des ressources aux valeurs énergétiques élevées similaires ou proches d'homologues tempérés sont disponibles. Les nombreuses ressources «protéiques» ont en revanche des valeurs qui ne «rivalisent» qu'exceptionnellement avec le soja. Des stratégies particulières d'utilisation de certaines ressources sont nécessaires du fait de la présence de métabolites secondaires aux activités antinutritionnelles. En intraressource, les variabilités induites par la gestion (âge du fourrage, mode d'alimentation...) et la technologie utilisée (élimination de facteurs antinutritionnels, mode d'extraction, usinage des grains de céréales) qui affectent aussi bien la valeur énergétique que protéique, sont souvent supérieures à celles résultant de la génétique. Des ressources de bonne valeur alimentaire sont donc disponibles en zone tropicale à condition d'y appliquer la bonne gestion et de choisir l'espèce animale adéquate pour leur valorisation. L'information accumulée sur la valeur alimentaire des ressources tropicales est abondante. L'accès aux données n'est pas toujours aisé du fait des stratégies de publication souvent ciblée sur l'échelle régionale. L'information peut être partielle (certains critères de la composition chimique). Les résultats peuvent être fortement liés au contexte dans lequel ces données ont été produites ce qui limite leur généralisation. Une étape importante pour l'avenir serait le regroupement de ces données avec la perspective de dégager des lois générales tel que permet de l'envisager le projet en cours de tables de valeur alimentaire (AFZ-INRA-CIRAD). 


\begin{abstract}
Tropical resources: availability and feed value

Availability and sources of variation in the feed value of tropical plant resources and agro-industry by-products were studied. There is a large diversity of feed resources (grass, legume, fodder trees, grains, tubers, co-culture, by-products of agro-industries) reflecting the great diversity of more or less intensified farming systems that includes feeding the different crops to livestock at variable levels. Feeds may be identical to those (soybean, corn) used in temperate zones, especially in modern farms. They can also be classified by their botanical origin (sorghum, tubers, fodder, and fodder trees), their composition (frequent presence of secondary metabolites) and treatment technology (agro-products from artisanal food) that they have suffered. There is great variability between and within feed value of resources. Whatever the animal species, high energy value resources, similar or close to temperate counterparts, are available. In contrast, the many protein-resources have values that do not «compete» with soybeans. Specific strategies to use certain resources are necessary because of the presence of secondary metabolites with antinutritional activities. Intra resource, management (fodder age, feeding strategy...) and the technology used (elimination of antinutritional factors, method of oil extraction from oilseeds, processing of cereal grains) induces variabilities that affect both the energy and protein values and that are often higher than those resulting from genetic origins. High feed value resources are available in the tropics provided that one applies the proper management and chooses the right animal species for their valorsiation. The accumulated information on the feed value of tropical resources is abundant. Access to data is not always easy because the publication strategies are often focused on a regional scale. Information can be partial (some criteria of chemical composition). The results can be strongly linked to the context in which they were produced, which limits their generalisation. An important step for the future is the collection of these data with the prospect of generating such general laws. This would be possible through the current FV table project (AFZ-INRA-CIRAD).
\end{abstract}

ARCHIMÈDE H., BASTIANELLI D., BOVAL M., TRAN G., SAUVANT D., 2011. Ressources tropicales : disponibilité et valeur alimentaire. In : Numéro spécial, Elevage en régions chaudes. Coulon J.B., Lecomte P., Boval M., Perez J.M. (Eds). INRA Prod. Anim., 24, 23-40. 
